\title{
Identification and Characterization of Pleural Neurons that Inhibit Tail Sensory Neurons and Motor Neurons in Aplysia: Correlation with FMRFamide Immunoreactivity
}

\author{
Yanli Xu, Leonard J. Cleary, and John H. Byrne \\ Department of Neurobiology and Anatomy, University of Texas Medical School, Houston, Texas 77225
}

\begin{abstract}
Neurons on the rostral edge of the ventral surface of the right pleural ganglion were identified as elements of the circuit mediating the defensive tail withdrawal reflex of $A p l y$ sia. These neurons produced IPSPs in tail sensory neurons and were classified into two groups, $\mathrm{RPI}_{4}$ and $\mathrm{RPI}_{5}$, according to their affinity for an antibody directed against FMRFamide. $\mathbf{R P I}_{4}$ was not FMRFamide immunoreactive, and $\mathbf{R P I}_{5}$ was. $\mathbf{R P I}_{4}$ and $\mathrm{RPI}_{5}$ were found to have different electrophysiological profiles. The summated IPSPs in sensory neurons produced by $\mathrm{RPI}_{4}$ developed more rapidly and had a shorter duration than those produced by $\mathrm{RPI}_{5}$. In addition, $\mathrm{RPI}_{4}$ produced IPSPs in the tail motor neurons, whereas $\mathrm{RPI}_{5}$ did not. Both $\mathrm{RPI}_{4}$ and $\mathrm{RPI}_{6}$ received excitatory synaptic inputs from stimulation of the pleural-abdominal connective as well as peripheral nerves P8 and P9, which innervate the tail and posterior part of the animal's body. These inputs were sufficient to elicit spikes. In $\mathrm{RPI}_{4}$, the excitatory synaptic inputs were followed by short and transient hyperpolarization, whereas in $\mathbf{R P I}_{5}$, the excitatory synaptic inputs were followed by slow and long-lasting hyperpolarization. Excitatory inputs elicited in $\mathrm{RPI}_{4}$ by stimulation of peripheral nerves appeared to be mediated, at least in part, by activation of tail sensory neurons. Intracellular stimulation of sensory neurons produced EPSPs in $\mathrm{RPI}_{4}$ that appeared to be monosynaptic. These results suggest that inhibitory interneurons underlying the circuit of the tail withdrawal reflex may play roles in mediating or modulating neuronal responses to tail stimulation. By inhibiting tail sensory and motor neurons, these interneurons may reduce the effectiveness of an animal's response to stimulation of the tail.
\end{abstract}

[Key words: tail-withdrawal reflex, FMRFamide, myomodulin, sensory neuron, motor neuron, inhibition, neural circuit, Aplysia]

The sensory and motor neurons that mediate the tail withdrawal reflex in Aplysia have been identified (Walters et al., 1983), but little is known about the role of interneurons in the circuit

\footnotetext{
Received April 8, 1993; revised Oct. 11, 1993; accepted Nov. 17, 1993.

We thank J. R. Goldsmith, F. Nazif, J. P. Pieroni, J. L. Raymond, and S. Sugita for their helpful discussions and comments on an earlier draft of the manuscript, Dr. K. Weiss for providing the anti-myomodulin antibody, and T. Vicknair for assistance with the illustrations. This research was supported by NIMH Award MH 00649 and NIH Grant NS 19895 to J.H.B.

Correspondence should be addressed to John H. Byrne, Department of Neurobiology and Anatomy, University of Texas Medical School

at Houston, P.O. Box 20708, Houston, TX 77225.

Copyright (C) 1994 Society for Neuroscience $0270-6474 / 94 / 143565-13 \$ 05.00 / 0$
}

underlying the reflex. Neurons with inhibitory effects on tail sensory neurons may be elements of the reflex circuitry since sensory neurons are hyperpolarized by stimulation of the animal's body wall outsidc of thcir excitatory receptive fields (Walters et al., 1983). Behavioral inhibition of the tail withdrawal reflex has not been demonstrated, but circuits for central arousal may suppress defensive reflexes under appropriate circumstances (Teyke et al., 1990). Evidence for inhibition of withdrawal reflexes in Aplysia has been obtained primarily from studies of the siphon-gill withdrawal reflex, which is mediated by neurons located in the abdominal ganglion. For example, strong tail shock transiently inhibits the siphon-gill withdrawal reflex (Krontiris-Litowitz et al., 1987; Mackey et al., 1987; Marcus et al., 1988; Rankin and Carew, 1988, 1989; Wright et al., 1991). This may be due, at least in part, to the effects of pleural interneuron $\mathrm{LPl}_{16}$, which produces presynaptic inhibition of the siphon sensory neurons and decreases the amplitude of the monosynaptic EPSP produced in a siphon motor neuron by a sensory neuron (Mackey et al., 1987; Small et al., 1992). Interneuron L16 in the abdominal ganglion may also contribute to inhibition of the siphon-gill withdrawal reflex. L16 decreases the amplitude of complex EPSPs in siphon motor neurons elicited by either branchial nerve stimulation or water jet stimuli (Hawkins et al., 1981b; Wright and Carew, 1990).

Several neurotransmitters that inhibit sensory neurons in the CNS of Aplysia have been identified, including the tetrapeptide FMRFamide (Phe-Met-Arg-Phe-NII ${ }_{2}$ ). This peptide hyperpolarizes both pleural and abdominal sensory neurons, decreases their excitability, and shortens the duration of their action potentials (Abrams et al., 1984; Ocorr and Byrne, 1985; Belardetti et al., 1987; Critz et al., 1991; Ichinose and Byrne, 1991; Pieroni and Byrne, 1992). In addition, synaptic transmission between sensory and motor neurons is also reduced (Mackey et al., 1987; Piomelli et al., 1987; Montarolo et al., 1988; Pieroni and Byrne, 1992; Small et al., 1992). These effects are due, at least in part, to the ability of FMRFamide to increase the probability of opening of the S-K $\mathrm{K}^{+}$channel (Ocorr and Byrne, 1985; Belardetti et al., 1987; Belardetti and Siegelbaum, 1988; Ichinose and Byrne, 1991). Although FMRFamide-immunoreactive (FMRFamideIR) neurons are distributed throughout the CNS of Aplysia (Weiss et al., 1984; Brown et al., 1985; Lo et al., 1987; Small et al., 1992), only the pleural neuron $\mathrm{LPl}_{16}$ has been shown to elicit these effects as a result of intracellular stimulation (Mackey et al., 1987; Small et al., 1992).

Myomodulin is another peptide with inhibitory effects on sensory neurons of Aplysia. This peptide produces spike narrowing in a subset of cerebral sensory neurons $\left(\mathrm{CM}-\mathrm{S}_{\mathrm{B}}\right)$ (Rosen 


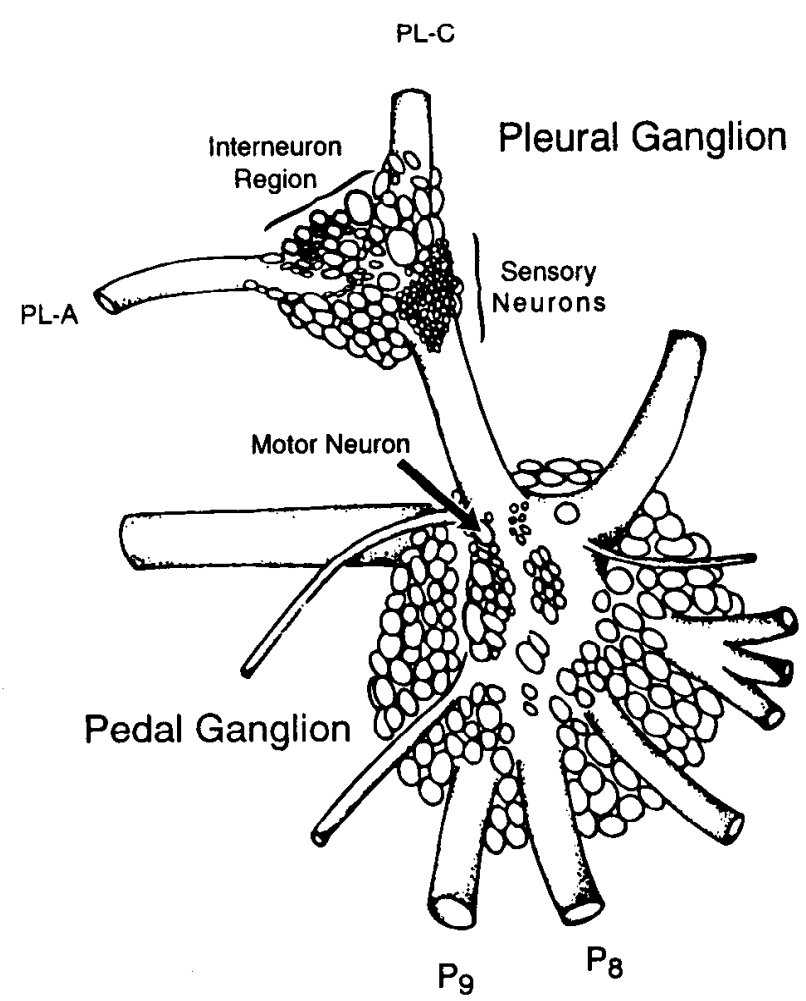

Figure 1. Schematic diagram of the right pleural and pedal ganglia. The pleural sensory neurons lie on the ventral surface of the pleural ganglion at the root of the pleural-pedal connective. Tail motor neurons are located in the pedal ganglion (arrow) and project out the posterior pedal nerve $\left(P_{9}\right)$. The middle pedal nerve $\left(P_{\gamma}\right)$ is also labeled. Recordings were made from inhibitory interneurons located on the rostral edge of the ventral surface of the pleural ganglion, between the pleural-abdominal $(P L-A)$ and pleural-cerebral $(P L-C)$ connectives. Modified from Walters et al., 1983.

et al., 1989). In tail sensory neurons, myomodulin reverses the increase in excitability and spike duration produced by $5-\mathrm{HT}$ (Critz et al., 1991).

The transmitters released by some inhibitory interneurons remain unidentified, however, including those released by L30 in the abdominal ganglion and $\mathrm{RPl}_{4}$ in the right pleural ganglion. L30 is activated by LE siphon sensory neurons and hyperpolarizes L29 (Hawkins et al., 1981a). $\mathrm{RPl}_{4}$ hyperpolarizes tail sensory and motor neurons and inhibits the synaptic transmission between tail sensory and motor neurons (Buonomano et al., 1992).

In the present study, we investigated the inhibitory actions produced by neurons in the right pleural ganglion on tail sensory and motor neurons and attempted to identify the neurotransmitters contained in these inhibitory interneurons by using immunofluorescence techniques. Based on their immunoreactivity to anti-FMRFamide antibody, these inhibitory interneurons appeared to be of two types, the previously identified $\mathrm{RPI}_{4}$ (Buonomano et al., 1992) and the newly identified $\mathrm{RPl}_{5} . \mathrm{RPl}_{5}$ was FMRFamide-IR and $\mathrm{RPl}_{4}$ was not. Further, these two groups of neurons could be distinguished on the basis of their electrophysiological properties.

A preliminary report of these results appeared in abstract form (Xu et al., 1991).

\section{Materials and Methods}

Aplysia californica (120-300 gm) were obtained from Alacrity Marine Biological Specimens (Redondo Beach, CA), Marine Specimens Unlim- ited (Pacific Palisades, CA), and Marinus, Inc. (Long Beach, CA). Animals were housed in individual containers at $15^{\circ} \mathrm{C}$ in aquaria filled with artificial seawater (ASW; Instant Ocean, Aquarium Systems, Mentor, $\mathrm{OH}$ ) and fed dried seaweed.

Before dissection, animals were anesthetized by injection of a volume of isotonic $\mathrm{MgCl}$, equal to approximately one-half of their body volume. The right pleural and pedal ganglia were removed and pinned to the floor of a chamber lined with Sylgard (Dow Corning, Midland, MI). The ganglia were desheathed in a 1:1 solution of isotonic $\mathrm{MgCl}_{2}$ and Tris-buffered ASW (pH 7.6) to expose the pleural ganglion and tail motor neurons located in the pedal ganglion. The pleural-abdominal connective and peripheral nerves P8 and P9 were each drawn into separate suction electrodes for electrical stimulation. After the dissection was completed, the bathing medium was replaced with ASW. All experiments were performed at room temperature $\left(\sim 21^{\circ} \mathrm{C}\right)$.

Intracellular recordings were performed using microelectrodes (3-6 $\mathrm{M} \Omega$ ) filled with $3 \mathrm{M} \mathrm{K}$-acetate. Tail sensory and motor neurons were identified by their size, location, and electrophysiological properties (Walters et al., 1983). Inhibitory interneurons were identified by their position and the IPSPs that they produced in tail sensory neurons. Interneurons were activated with brief (1-6 sec) constant-current depolarizing pulses. Some attempts were made to fire a uniform number of spikes in the different interneurons by varying the intensity and duration of the stimuli. This trial-and-error approach was only approximate because the number of tests had to be minimized in order to avoid cumulative desensitization of the responses. This issuc is discussed further in the Results. In some preparations it was necessary to hyperpolarize interneurons and motor neurons to prevent spontaneous action potentials. When recording sessions were completed, electrophysiologically identified inhibitory interneurons were impaled with a second electrode containing 5\% Lucifer yellow (Molecular Probes) in distilled water and filled by iontophoresis ( $5 \mathrm{nA}, 500 \mathrm{msec}$ hyperpolarizing pulses at $1 \mathrm{~Hz}$ for $30-120 \mathrm{~min}$ ). The filled cells were then photographed as whole-mounts under epifluorescence illumination with a Zeiss Axiophot microscope using appropriate filters (i.e., Zeiss 05 filter combination).

Immunohistochemical procedures were performed using methods modified from Kistler et al. (1985). The pleural ganglion was fixed for $4 \mathrm{hr}$ at room temperature with $4 \%$ paraformaldehyde in $10 \mathrm{~mm}$ phosphate-buffered saline (PBS) containing 30\% sucrose. The ganglion was then rinsed overnight in PBS containing 30\% sucrose and sectioned on a cryostat at nominal thickness of $10 \mu \mathrm{m}$. Sections were rinsed for 20 min in PBS containing $0.25 \%$ saponin and permeabilized by serial dehydration through $50 \%, 70 \%, 80 \%$, and $95 \%$ ethanol and rehydration to PBS. Sections were then exposed to normal goat serum diluted in PBS-saponin for $30 \mathrm{~min}$ at room temperature. The slides were incubated in either rabbit anti-FMRFamide antisera (INCSTAR), anti-myomodulin antisera (gift of Dr. K. Weiss, Mt. Sinai School of Medicine, NY), or anti-histamine antisera (INCSTAR) overnight at $4^{\circ} \mathrm{C}$. All antisera were in 1:300 dilution of PBS-saponin. Sections were rinsed, incubated for $30 \mathrm{~min}$ at room temperature in goat anti-rabbit antiserum conjugated to Texas red (diluted 1:50; Molecular Probes). After mounting with glycerol, the sections were viewed with a Zeiss epifluorescence microscope using filters selective for Lucifer yellow (05) or Texas red (00), and then photographed with Kodak TMAX 400 film.

\section{Results}

Characterization of $\mathrm{RPl}_{4}$ and $\mathrm{RPl}_{5}$

In this study, inhibitory interneurons in the pleural ganglion were identified on the basis of their ability to produce IPSPs in tail sensory neurons located in the ventrocaudal cluster of the right pleural ganglion (Fig. 1). Neurons with this ability tended to be located on the rostral edge of the ventral surface of the ganglion. This is also the location of $\mathrm{RPl}_{4}$, an inhibitory interneuron identified previously (Buonomano et al., 1992). Inhibitory interneurons in this cluster were usually spontaneously active and were $100-200 \mu \mathrm{m}$ in diameter. Bursts of spikes produced summated IPSPs in sensory neurons located throughout the ipsilateral ventrocaudal cluster. The amplitudes of these IPSPs ranged from 0.4 to $6.0 \mathrm{mV}$ (e.g., Figs. 4-6). Single spikes never elicited observable IPSPs. Additional features of the summated IPSPs are described below. 

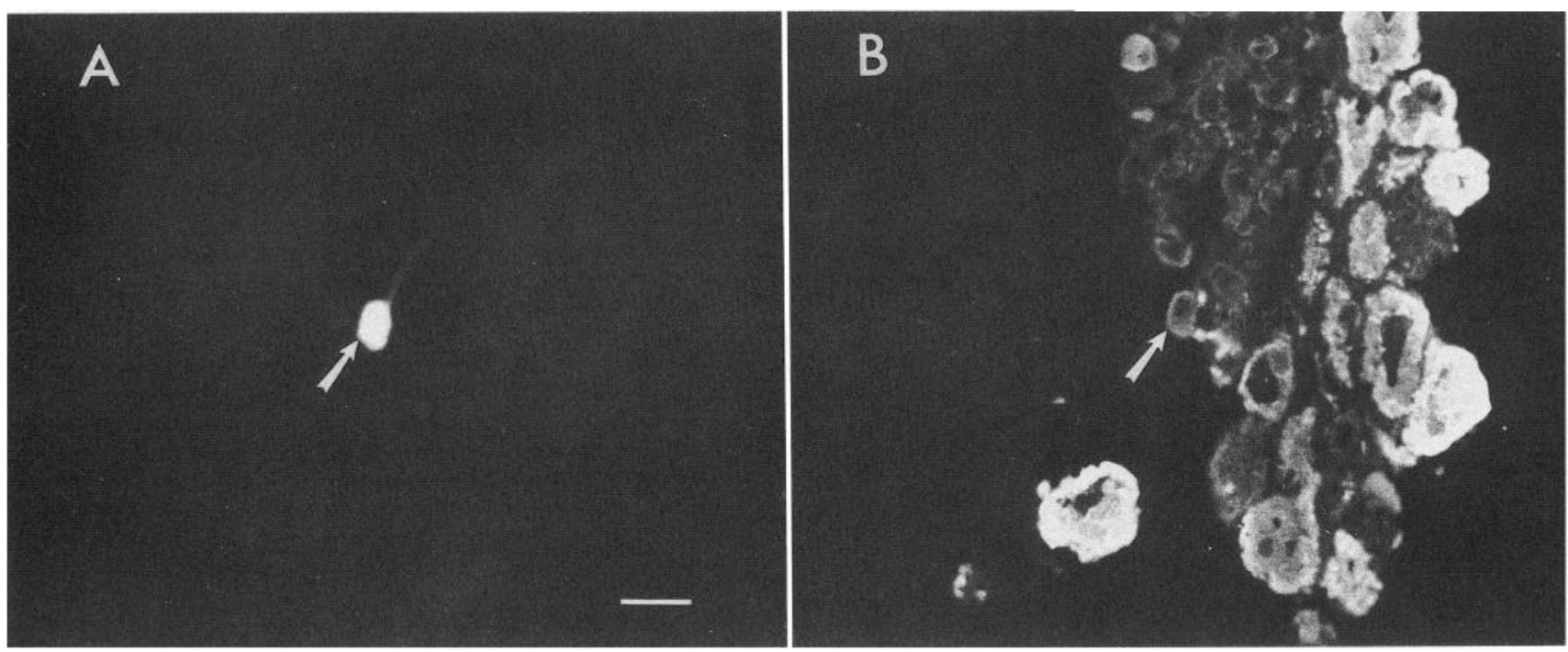

Figure 2. Immunofluorescence shows that $\mathrm{RPl}_{4}$ is not FMRFamide-IR. $A$, Fluorescence photomicrograph showing the cell body of an inhibitory interneuron injected with Lucifer yellow (arrow). B, Fluorescence photomicrograph of the FMRFamide-IR structures in the same field. Although there were numerous immunopositive neurons in the pleural ganglion, the injected inhibitory interneuron (arrow) was not immunoreactive for FMRFamide. Scale bar, $200 \mu \mathrm{m}$.

Although numerous cell bodies containing the inhibitory peptide FMRFamide are located in the pleural ganglion (Weiss et al., 1984; Brown et al., 1985; Lo et al., 1987; Small et al., 1992), previous studies suggested that $\mathrm{RPl}_{4}$ does not contain FMRFamide (Buonomano et al., 1992). To confirm and extend this study, all inhibitory interneurons were injected with Lucifer yellow after electrophysiological recordings. The ganglia were then sectioned and stained for the presence of FMRFamide using a secondary antibody coupled to Texas red. Most neurons did not cross-react with the antibody $(N=37)$, and these neurons were tentatively identified as $\mathrm{RPl}_{4}$ (Fig. 2). $\mathrm{RPl}_{4}$ contained neither myomodulin $(N=17)$ nor histamine $(N=8)$ (not shown). Some FMRFamide-IR neurons were also observed, however $(N=10)$, and these neurons were tentatively identified as a new cell type, $\mathrm{RPl}_{5}$ (Fig. 3).

The identification of $\mathrm{RPl}_{4}$ and $\mathrm{RPl}_{5}$ based on their transmitter content was extended by examining several electrophysiological properties of these inhibitory interneurons. These include (1) the time course of the summated IPSPs produced in tail sensory neurons, (2) the output to tail motor neurons, and (3) the input from stimulation of the pleural-abdominal connective and peripheral nerves P8 and P9. Population data are provided throughout the text, but to highlight the conspicuous differences between $\mathrm{RPl}_{4}$ and $\mathrm{RPl}_{5}$, illustrations derived from a single pair of $\mathrm{RPl}_{4}$ and $\mathrm{RPl}_{5}$ neurons are used whenever possible $\left(\mathrm{RPl}_{4}\right.$ in Figs. 2, 4, 7, 9; $\mathrm{RPl}_{5}$ in Figs. 3, 5, 8, 10).

\section{$\mathrm{RPl}_{4}$ and $\mathrm{RPl}_{5}$ elicited distinctive responses in sensory and motor neurons}

Bursts of action potentials in both $\mathrm{RPl}_{4}$ and $\mathrm{RPl}_{5}$ produced summated IPSPs in tail sensory neurons. Summated IPSPs produced by $\mathrm{RPl}_{4}$ (Fig. 4) developed relatively rapidly [average half-
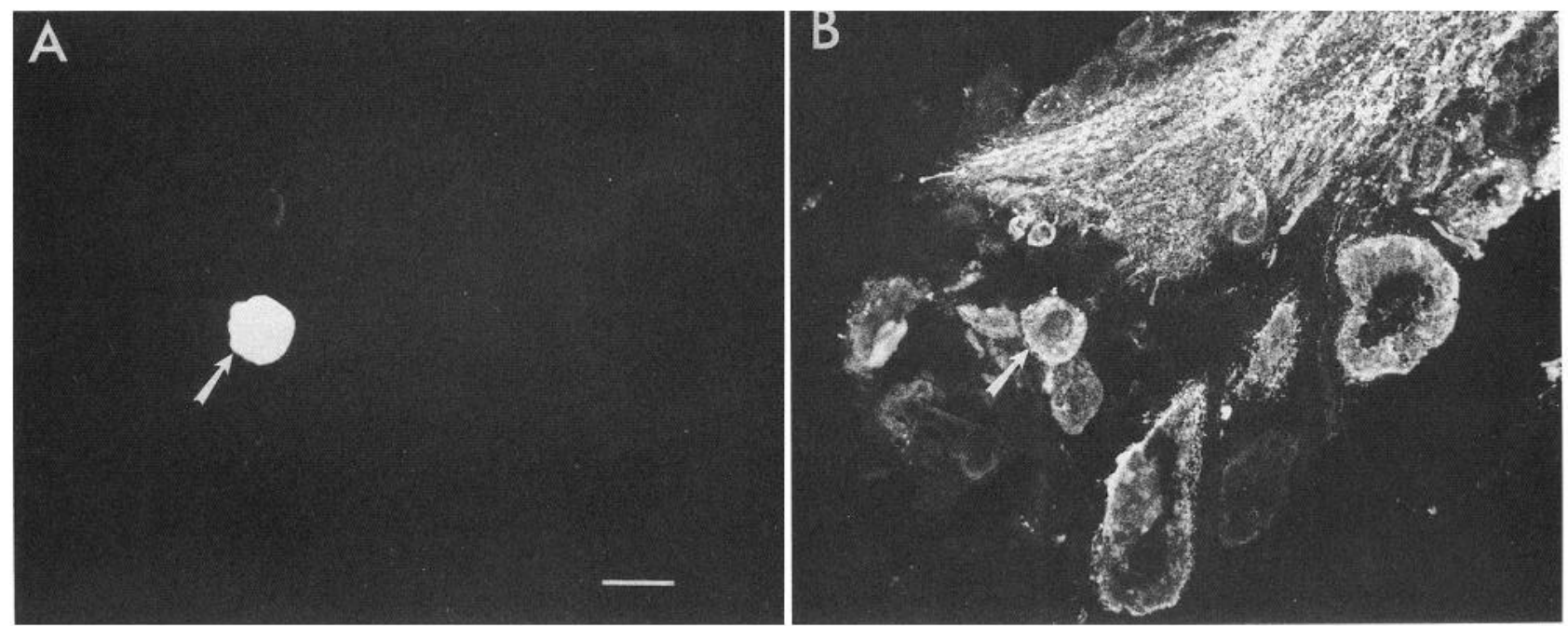

Figure 3. Immunofluorescence shows that $\mathrm{RPI}_{5}$ is FMRFamide-IR. A, Fluorescence photomicrograph showing a section of the cell body of an inhibitory interneuron injected with Lucifer yellow (arrow). B. Fluorescence photomicrograph of FMRFamide-IR structures in the same field, showing that the injected inhibitory interneuron (arrow) was immunoreactive for FMRFamide. Scale bar, $200 \mu \mathrm{m}$. 

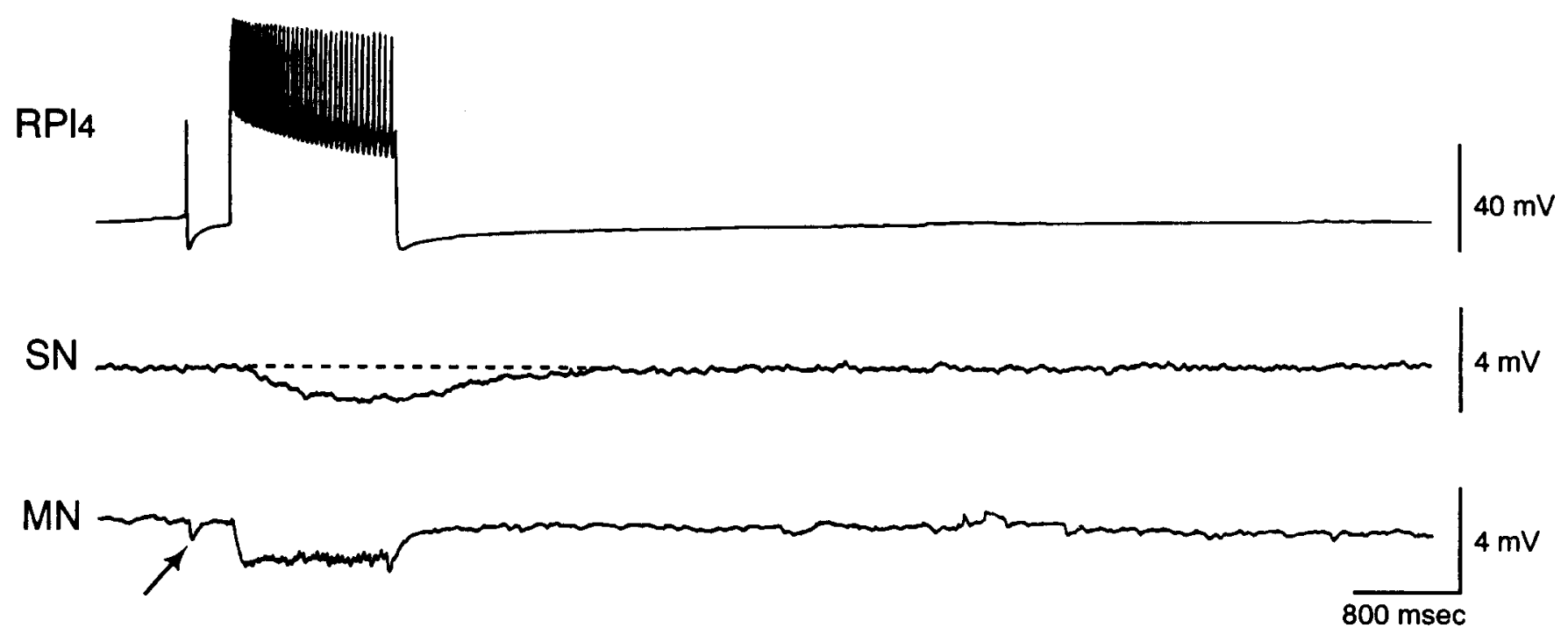

Figure 4. Intracellular stimulation of $\mathrm{RPl}_{4}$ produces IPSPs both in sensory neurons and motor neurons. High-frequency burst of spikes elicited in the $\mathrm{RPl}_{4}$ shown in Figure 2 produced IPSPs in a sensory neuron $(S N)$ and a motor neuron $(M N)$. Note the relatively fast appearance (compare Fig. 5) of the hyperpolarization in the sensory neuron (half-time to maximal hyperpolarization $=400 \mathrm{msec}$ ). Upon termination of the interneuron stimulation, membrane potential of the sensory neuron rapidly repolarized to baseline (half-time to repolarization $=480 \mathrm{msec}$ ). Note that a single spontaneous spike in the $\mathrm{RPl}_{4}$ produced a single IPSP in the motor neuron (arrow).

time to maximal hyperpolarization $=493 \pm 35 \mathrm{msec}($ mean \pm $\mathrm{SEM}), N=20$ ], and upon termination of the interneuron stimulation, recovered relatively rapidly to baseline (average halftime to repolarization $=440 \pm 36 \mathrm{msec}, N=20$ ). Connections that produced summated IPSPs with amplitudes less than 0.8 $\mathrm{mV}$ were excluded from this analysis because of the difficulty in measuring the time course. A single spike in an interneuron did not elicit an observable IPSP in any sensory neurons recorded.

Intracellular stimulation of $\mathrm{RPl}_{4}$ also produced IPSPs in tail motor neurons $(N=14)$. In some preparations $(N=8$ of 14), one single spike in $\mathrm{RPl}_{4}$ elicited a discrete IPSP in the motor neuron (e.g., Fig. 4, arrow). In these preparations, the connections between the inhibitory interneurons and the motor neurons appeared to be monosynaptic, since the IPSPs in the motor neurons always showed a constant latency after repetitive stimulation of $\mathrm{RPl}_{4}$. In one preparation, we confirmed a previous result (Buonomano et al., 1992) that the IPSPs elicited in the motor neuron by stimulation of $\mathrm{RPl}_{4}$ persisted in the presence of a high-divalent cation solution (data not shown). Monosynapticity of the connections between $\mathrm{RPl}_{4}$ and sensory neurons was difficult to test because individual IPSPs in sensory neurons were too small to analyze. In one experiment, the summated IPSPs in the sensory neuron persisted, but became smaller, in
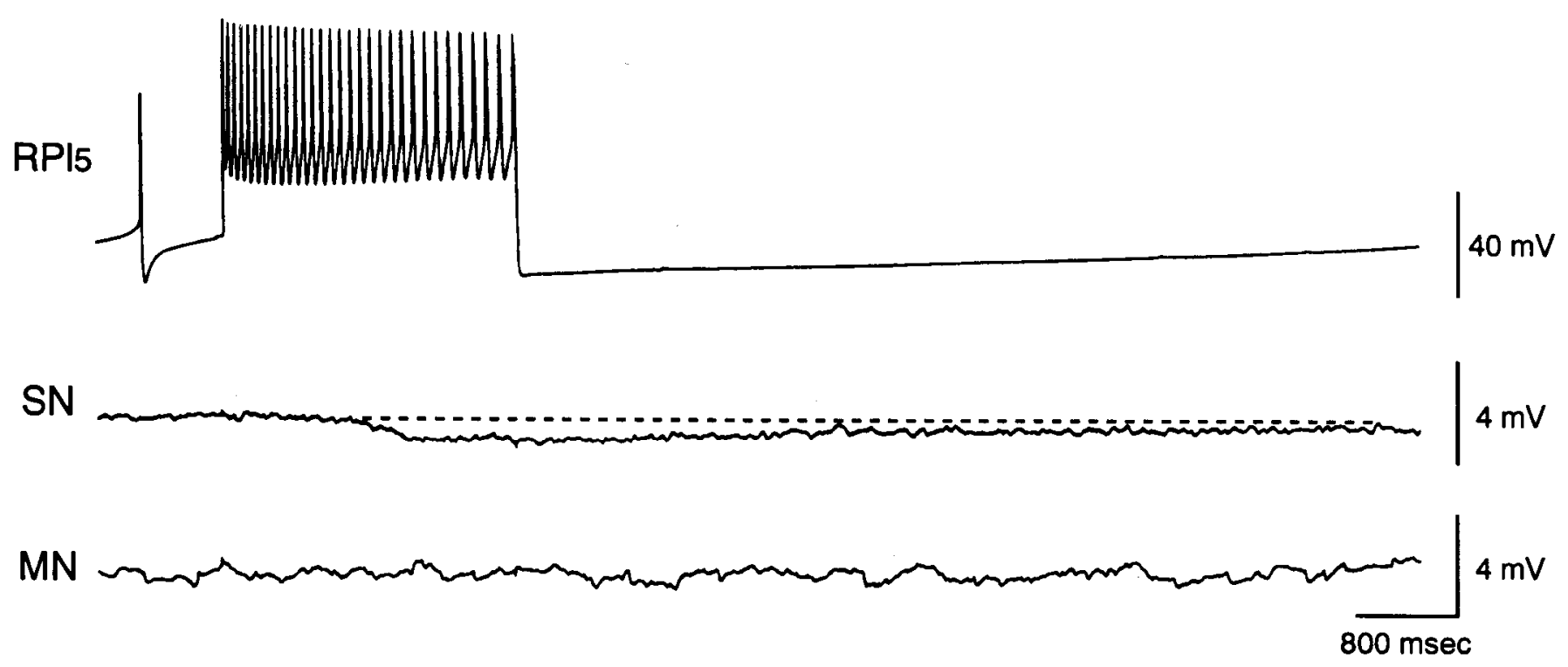

Figure 5. Intracellular stimulation of $\mathrm{RPl}_{5}$ produces IPSPs in the sensory neurons, but not in the motor neurons. High frequency of firing in the $\mathrm{RPl}_{5}$ shown in Figure 3 produced IPSPs in a sensory neuron $(S N)$ but not in a motor neuron $(M N)$. Compared with the effects of the RPl ${ }_{4}$ shown in Figure 4, the hyperpolarization produced by the $\mathrm{RPI}_{5}$ took a longer time to reach its peak amplitude (half-time to maximal hyperpolarization $=1.1 \mathrm{sec}$ ). Moreover, upon termination of the stimulation, the membrane potential recovered relatively slowly to baseline (half-time to repolarization $=2.1 \mathrm{sec})$. 

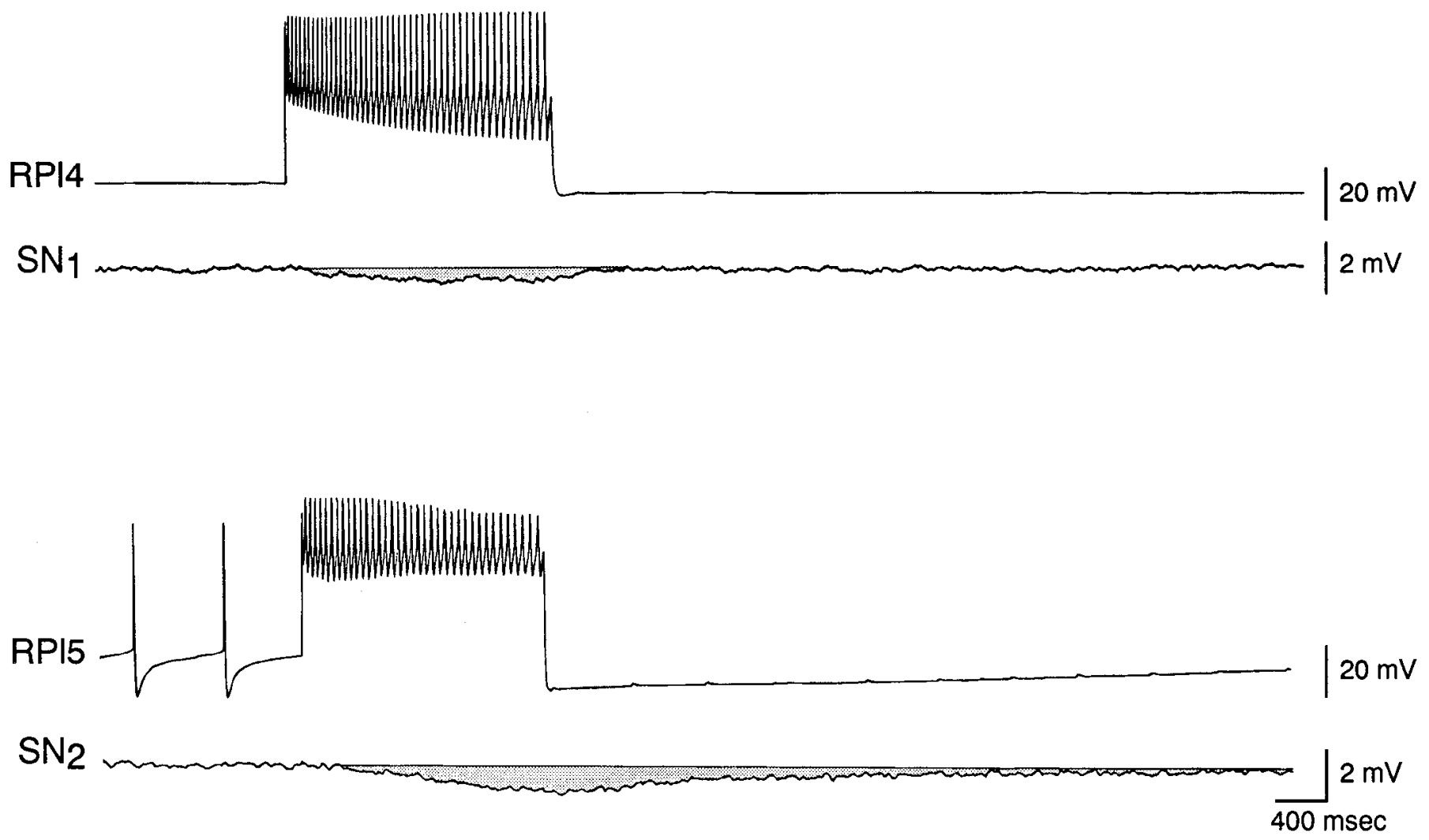

Figure 6. The longer duration of the hyperpolarization in $\mathrm{RPl}_{5}$ was not due to the longer duration of firing. In this example, the number of action potentials in $\mathrm{RPl}_{4}$ was 47 and the number of action potentials in $\mathrm{RPl} 5$ was 38 . For $\mathrm{RPl}_{4}$, the half-time to maximal hyperpolarization was 380 msec; the half-time to repolarization was $360 \mathrm{msec}$. For $\mathrm{RPl}_{5}$, the half-time to maximal hyperpolarization was $1000 \mathrm{msec}$; the half-time to repolarization was $880 \mathrm{msec}$.

the presence of a high-divalent cation solution (Byrne et al., 1978).

Activation of $\mathrm{RPI}_{5}$ also produced summating IPSPs in tail sensory neurons (Fig. 5). Compared with $\mathrm{RPl}_{4}, \mathrm{RPI}_{5}$ produced IPSPs in sensory neurons that developed slowly (average halftime to maximal hyperpolarization $=1.2 \pm 0.2 \mathrm{sec}, N=7$ ). In addition, the membrane potential recovered more slowly to baseline upon termination of the stimulation (average half-time to repolarization $=1.1 \pm 0.2 \mathrm{sec}, N=7$ ). These differences in the time course of hyperpolarization and repolarization of the summated IPSPs, produced by $\mathrm{RPl}_{4}$ and $\mathrm{RPI}_{5}$ were statistically significant (hyperpolarization: $t_{25}=5.84, P<0.001$; repolarization: $t_{25}=4.27, P<0.001$ ). Because of their undetectable amplitude, we did not analyze the half-time for hyperpolarization or repolarization of the individual IPSPs produced by $\mathrm{RPI}_{4}$ and $\mathrm{RPI}_{5}$ in sensory neurons. Intracellular stimulation of $\mathrm{RPI}_{5}$ did not produce IPSPs in tail motor neurons, regardless of whether the postsynaptic cell was at resting membrane potential or hyperpolarized (Fig. 5). This is consistent with the lack of an axon projecting to the pedal ganglion (see Morphological features of $\mathrm{RPl}_{4}$ and $\mathrm{RPl}_{5}$, below).

Because cumulative desensitization was a concern (see Materials and Methods), there was insufficient time to elicit the same number of action potentials in each $\mathrm{RP}_{4}$ or $\mathrm{RPl}_{5}$ that was tested (e.g., Figs. 4, 5). Systematic differences in the number and/or frequency of spikes could in principle account for differences in the duration of the responses. However, the average numbers of spikes per burst in $\mathrm{RPl}_{4}$ and $\mathrm{RPl}_{5}$ were similar [average number of spikes in $\mathrm{RPl}_{4}$ was $57 \pm 27$ (mean $\pm \mathrm{SD}$ ), $N$
$=18$; average number of spikes in $\mathrm{RPl}_{5}$ was $55 \pm 25$ (mean \pm $\mathrm{SD}$ ), $N=7$ ]. Moreover, within the range of spikes that were elicited, correlation analysis indicated that the number of spikes and the half-time for hyperpolarization or repolarization were not positively correlated. For $\mathrm{RPl}_{4}$, the correlation coefficient between the number of spikes and the half-time for hyperpolarization was $-0.036(P=0.886)$. The corrclation coefficient between the number of spikes and the half-time for repolarization was $-0.197(P=0.443)$. For $\mathrm{RPl}_{s}$, the correlation coefficient between the number of spikes and the half-time for hyperpolarization was $-0.554(P=0.199)$. The correlation coefficient between the nu.nber of spikes and the half-time for repolarization was $-0.327(P=0.476)$. An example of this lack of correlation is shown in Figure 6. Here, $\mathrm{RPl}_{4}$ was stimulated at a longer duration than $\mathrm{RPI}_{5}$, but the half-times for hyperpolarization and repolarization were still shorter. These analyses suggested that differences in the time course of summated IPSPs in sensory neurons produced by $\mathrm{RPl}_{4}$ and $\mathrm{RPl}_{5}$ could not be attributed to the differences in their firing properties.

Although the number of inhibitory interneurons per ganglion was not studied systematically, some observations were made regarding the topography of interneuron output. For example, we recorded from as many as two different $\mathrm{RPl}_{4}$ neurons in a single preparation, but never recorded from more than one $\mathrm{RPI}_{5}$ in a single preparation. Both $\mathrm{RPl}_{4}$ and $\mathrm{RPl}_{5}$ had divergent output to sensory neurons, since either cell could produce simultaneous IPSPs in at least two different sensory neurons. It is not known whether $\mathrm{RPl}_{4}$ and $\mathrm{RPl}_{5}$ converge onto individual sensory neurons, however. Output from $\mathrm{RPl}_{4}$ to tail motor neurons was also 


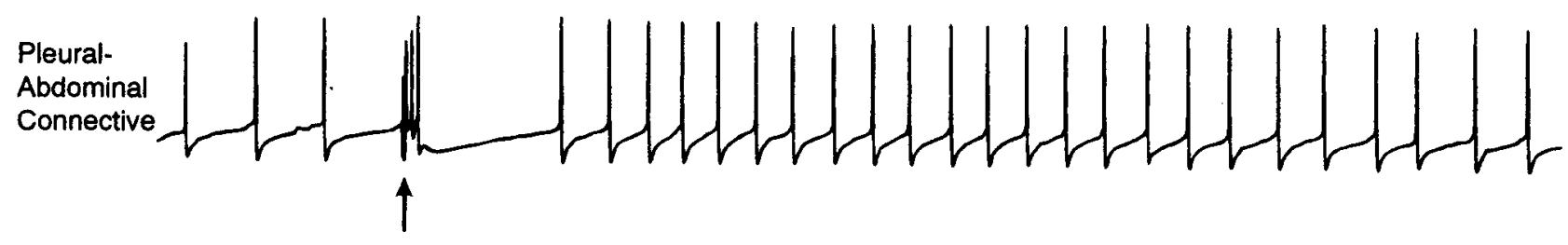

$\mathrm{P}_{8}$
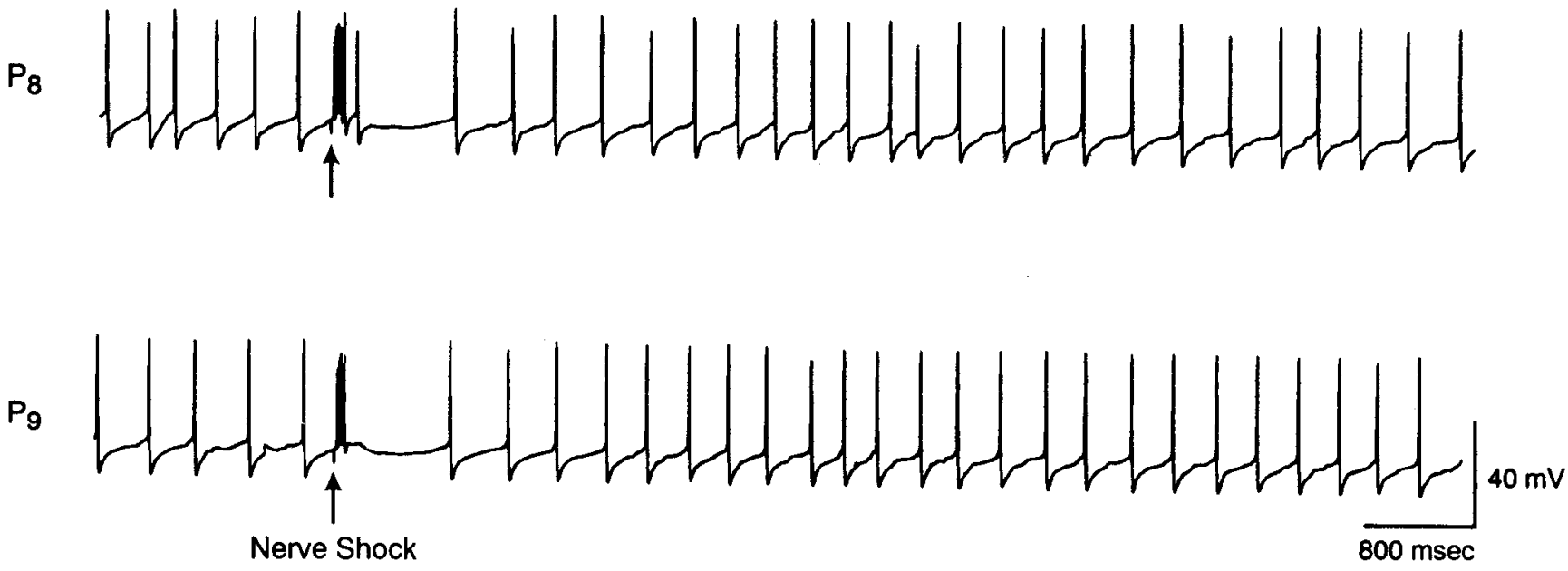

Figure 7. $\mathrm{RPl}_{4}$ receives excitatory synaptic inputs followed by short-lasting inhibition as a result of nerve shock. Responses of the same $\mathrm{RPl}_{4}$ shown in Figures 2 and 4 to electrical stimulation of the pleural-abdominal connective (top), peripheral nerves P8 (middle), and P9 (bottom). In each trace, a single $2 \mathrm{~mA}$, 3-msec-duration nerve shock (arrow) was delivered via the suction electrode. The inhibitory interneuron received excitatory synaptic inputs followed by weak and transient inhibition from all three nerves.
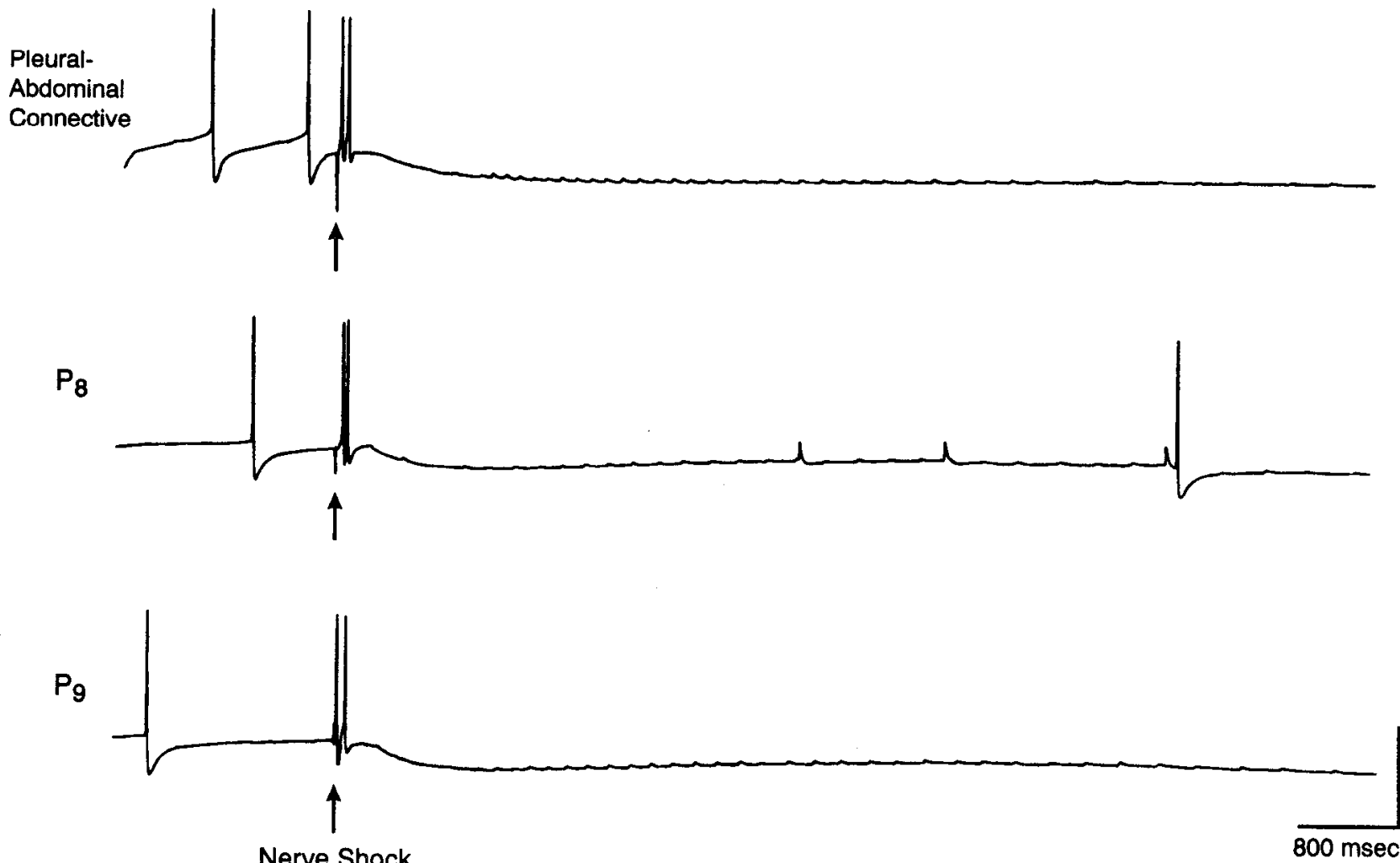

Nerve Shock

Figure 8. $\mathrm{RPl}_{5}$ receives excitation followed by long-lasting inhibition as a result of nerve shock. Responses of the same $\mathrm{RPl} \mathrm{s}_{5}$ shown in Figures 3 and 5 to electrical stimulation of the pleural-abdominal connective (top), peripheral nerves P8 (middle), and P9 (bottom). The inhibitory interneuron received excitatory synaptic inputs that produced action potentials. The excitatory input was followed by a long-lasting hyperpolarization. Responses of $\mathrm{RPl}_{5}$ to nerve shock differ from $\mathrm{RPl}_{4}$ primarily in the duration of the hyperpolarization. 


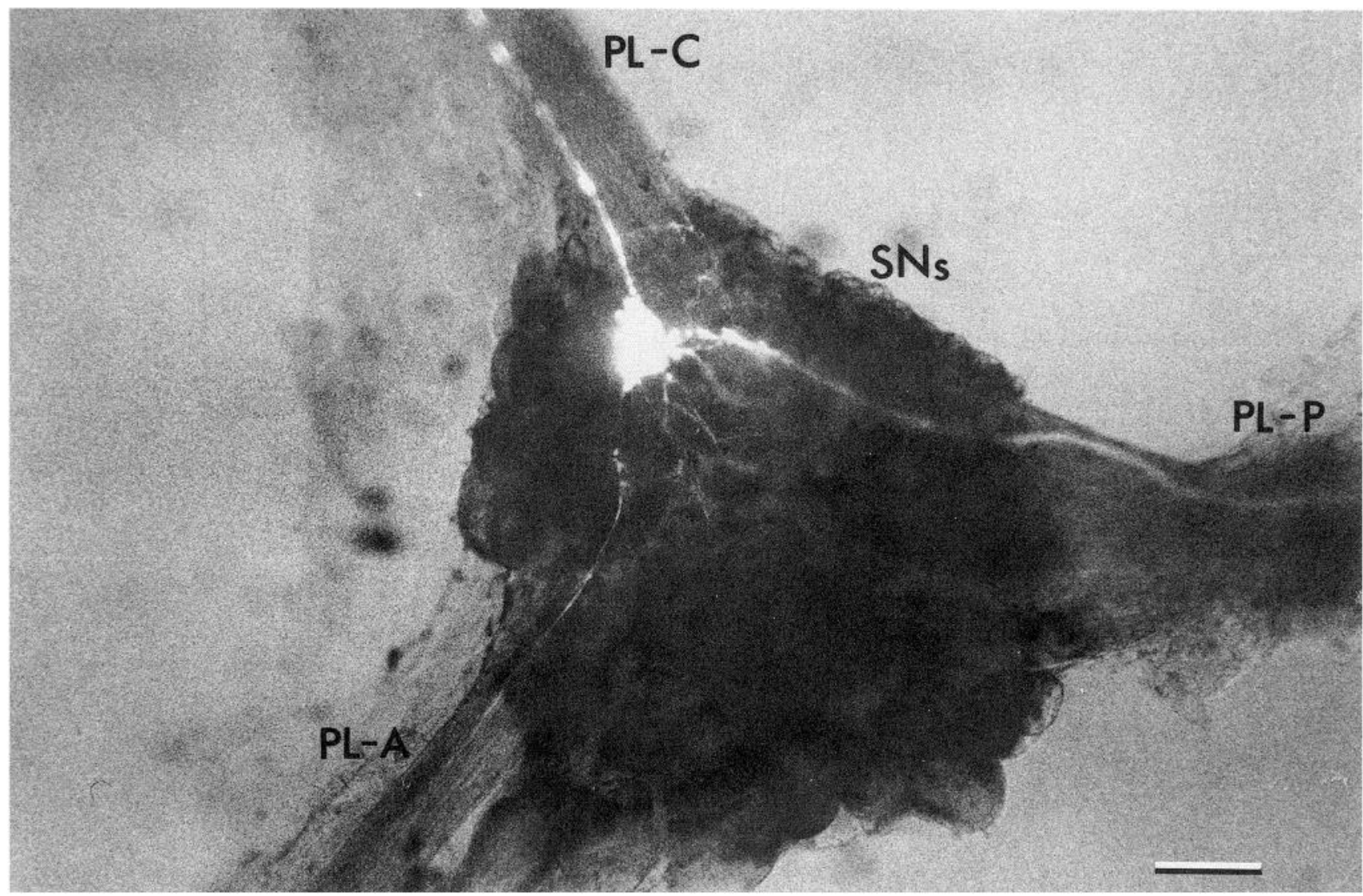

Figure 9. Injection of Lucifer yellow into $\mathrm{RPl}_{4}$ reveals axonal branches in all connectives exiting the pleural ganglion. Injection of Lucifer yellow into the same $\mathrm{RPl}_{4}$ described in Figures 2, 4, and 7 showed that this $\mathrm{RPl}_{4}$ had axonal branches in the pleural-pedal $(P L-P)$, pleural-abdominal $(P L$ $A)$, and pleural-cerebral $(P L-C)$ connectives. Small arborizations could also be seen underlying the sensory neuron cluster. Scale bar, $200 \mu \mathrm{m}$.

divergent. For example, in one experiment, stimulation of one $\mathrm{RPl}_{4}$ neuron produced IPSPs in two different motor neurons. Conversely, convergent input from two different $\mathrm{RPl}_{4} \mathrm{~s}$ onto a single tail motor neuron was also observed. Thus, the pattern of interconnectivity among different components in the circuit appears to be complex. Additional experiments will be required to detail the topography of interneuron output.

\section{$\mathrm{RPl}_{4}$ and $\mathrm{RPl}_{5}$ differed in response to stimulation of the pleural-abdominal connective and peripheral nerves}

As a first step toward investigating the source of input to inhibitory interneurons, we examined their responses to nerve shock applied to the pleural-abdominal connective and to the peripheral nerves $\mathrm{P} 8$ and $\mathrm{P} 9$, which innervate the posterior part of the animal, including the tail. Electrical stimulation of the connective and the peripheral nerves P8 and P9 produced excitatory synaptic inputs in $\mathrm{RPl}_{4}$ and $\mathrm{RPl}_{5}$. These inputs were sufficient to elicit action potentials. In $\mathrm{RPl}_{4}$, the excitatory synaptic inputs were followed by a relatively weak and short-lasting hyperpolarization (21 of 29 neurons) (Fig. 7). In some cases, antidromic spikes were elicited in response to nerve or connective stimulation, indicating the presence of an axon (pleuralabdominal connective, 1 of 29 neurons; P8, 5 of 29 neurons; $\mathrm{P} 9,6$ of 29 neurons). In $\mathrm{RPl}_{5}$, the action potentials evoked by connective or nerve shocks were followed by a long-lasting hyperpolarization over which a long train of low-frequency fast
EPSPs was typically superimposed (8 of 10 neurons) (Fig. 8). No antidromic spikes were elicited in $\mathrm{RPl}_{5}$ after stimulation of the nerves or connective.

The appearance of the late hyperpolarization in $\mathrm{RPl}_{4}$ was coupled to the initial excitatory discharge. It appeared to be synaptically driven rather than a postburst hyperpolarization because equivalent or higher-frequency bursts of spikes elicited by intracellular current pulses led to a smaller postburst hyperpolarization than the late hyperpolarization produced by nerve stimulation. Moreover, tactile stimuli that evoked a burst of spikes in $\mathrm{RPl}_{4}$ failed to recruit the late inhibition (D. V. Buonomano and J. H. Byrne, personal communication). Similarly, the late hyperpolarization in $\mathrm{RPl}_{5}$ also appeared to be synaptically driven. In one preparation, nerve shock elicited the late hyperpolarization in the absence of action potentials.

\section{Morphological features of $\mathrm{RPl}_{4}$ and $\mathrm{RPl}_{5}$}

After recording the electrophysiological properties of inhibitory interneurons, they were injected with Lucifer yellow by iontophoresis. Of $37 \mathrm{RPl}_{4}$ cells, the branching patterns of 16 were revealed. In the remaining cases, only the cell bodies were filled. Of the 16 successful fills, five cells showed axonal branches in all three connectives exiting the pleural ganglion (Fig. 9). Seven cells had axonal branches in the pleural-pedal and pleural-cerebral connectives, two had axons in pleural-cerebral and pleural-abdominal connectives, and two had axons in the pleural- 


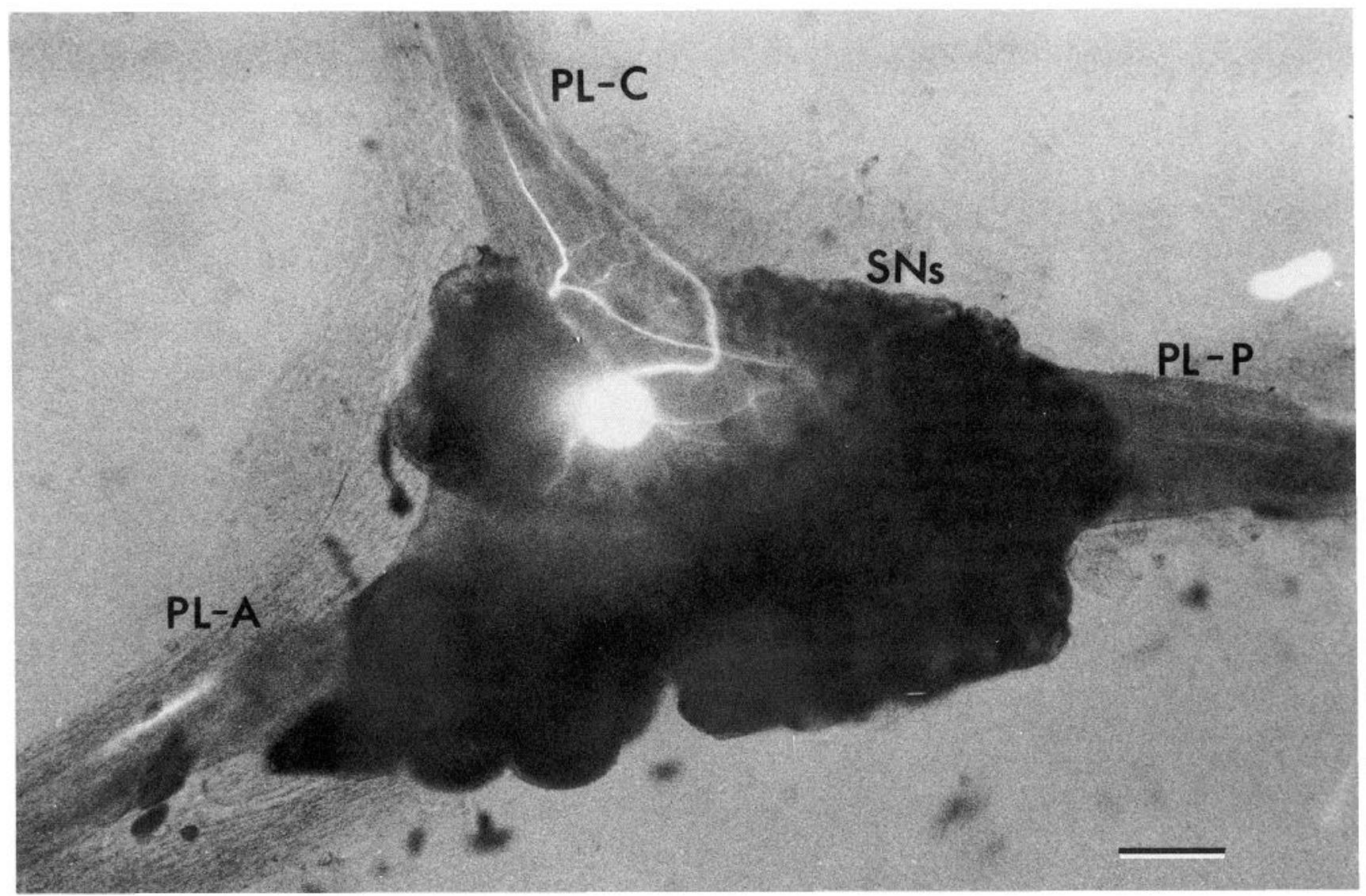

Figure 10. Injection of Lucifer yellow into $\mathrm{RPl}_{5}$ reveals axonal branches in the pleural-cerebral and pleural-abdominal connectives. Injection of Lucifer yellow into the same $\mathrm{RPI}_{5}$ described in Figures 3, 5, and 8 revealed two axonal branches in the pleural-cerebral connective, one branch in the pleural-abdominal connective, and small arborization within the pleural ganglion beneath the sensory neuron cluster. Branches of $\mathrm{RPl}_{5}$ were never found in the pleural-pedal connective. Scale bar, $200 \mu \mathrm{m}$.

pedal connective only. There were also multiple branches of axons within the pleural ganglion itself, especially in the vicinity of the cluster of sensory neurons. The presence of an axon in the pleural-pedal connective is consistent with the ability of $\mathrm{RPI}_{4}$ to elicit IPSPs in tail motor neurons because tail motor neurons do not send axons into the pleural ganglion (Cleary and Byrne, 1984). Moreover, these axonal processes presumably project through the pedal ganglion into the peripheral nerves, because stimulation of $\mathrm{P} 8$ and $\mathrm{P} 9$ elicited antidromic spikes in $\mathrm{RPl}_{4}$.

Of $10 \mathrm{RPI}_{5}$ neurons injected, four were filled successfully. Of these, two cells had axonal branches in the pleural-cerebral and pleural-abdominal connectives (Fig. 10) and two had branches only in the pleural-cerebral connective. No $\mathrm{RPl}_{5}$ neurons sent projections into the pleural-pedal connective, implying that $\mathrm{RPI}_{5}$ may not have direct synaptic connections with tail motor neurons.

In summary, axonal branching patterns of $\mathrm{RPl}_{4}$ and $\mathrm{RPl}_{5}$ revealed by electrophysiological and morphological studies were not always correlated. For $\mathrm{RPl}_{4}$, antidromic spikes were shown in both the connective and nerves (pleural-abdominal connective, 1 of 29 neurons; P8, 5 of 29 neurons; P9, 6 of 29 neurons). Morphological studies only revealed axonal branches in the pleural-abdominal connective ( 7 of 16 neurons). For $\mathrm{RPl}_{5}$, antidromic spikes were never shown in either the connective or nerves (10 neurons). Morphological studies revealed axonal branches in the pleural-abdominal connective (two of four neurons). The most common projection for both $\mathrm{RPl}_{4}$ and $\mathrm{RPI}_{5}$, however, was to the cerebral ganglion. We do not know if these axons terminated in the neuropil or projected out cerebral nerves.

\section{Sensory neurons and $\mathrm{RPl}_{4}$ were interconnected}

Inhibitory interneurons received excitatory synaptic inputs from electrical stimulation of the peripheral nerves P8 and P9 (Figs. $7,8)$. One possible source of synaptic input from peripheral nerves was the tail sensory neurons that project out these nerves. Consequently, we investigated whether individual sensory neurons would elicit EPSPs in the inhibitory interneurons. Figure 11 illustrates an example of one such experiment. A high-frequency burst of spikes in $\mathrm{RPl}_{4}$ produced IPSPs in a sensory neuron. A single action potential triggered in the same sensory neuron by a suprathreshold depolarizing current pulse produced an EPSP in the $\mathrm{RPl}_{4}$. Thus, a sensory neuron that excites an inhibitory interneuron could receive feedback inhibition from that interneuron $(N=2) . \mathrm{RPl}_{4}$ did not always receive excitatory input from the sensory neurons that they inhibited, however, and it could receive synaptic inputs from sensory neurons that were not followers $(N=4)$. Figure 12 illustrates such a preparation in which the interconnections between an interneuron and two different sensory neurons were examined. A single $\mathrm{RPl}_{4}$ inhibited one sensory neuron (Fig. $12 A 1, \mathrm{SN}_{1}$ ), but not the other (Fig. $12 B 1, \mathrm{SN}_{2}$ ). The same interneuron received excitatory synaptic inputs from the sensory neuron $\left(\mathrm{SN}_{2}\right)$ that was not a follower, but not from the sensory neuron $\left(\mathrm{SN}_{1}\right)$ that was a follower (Fig. 12A2,B2). This circuit configuration may explain the hy- 

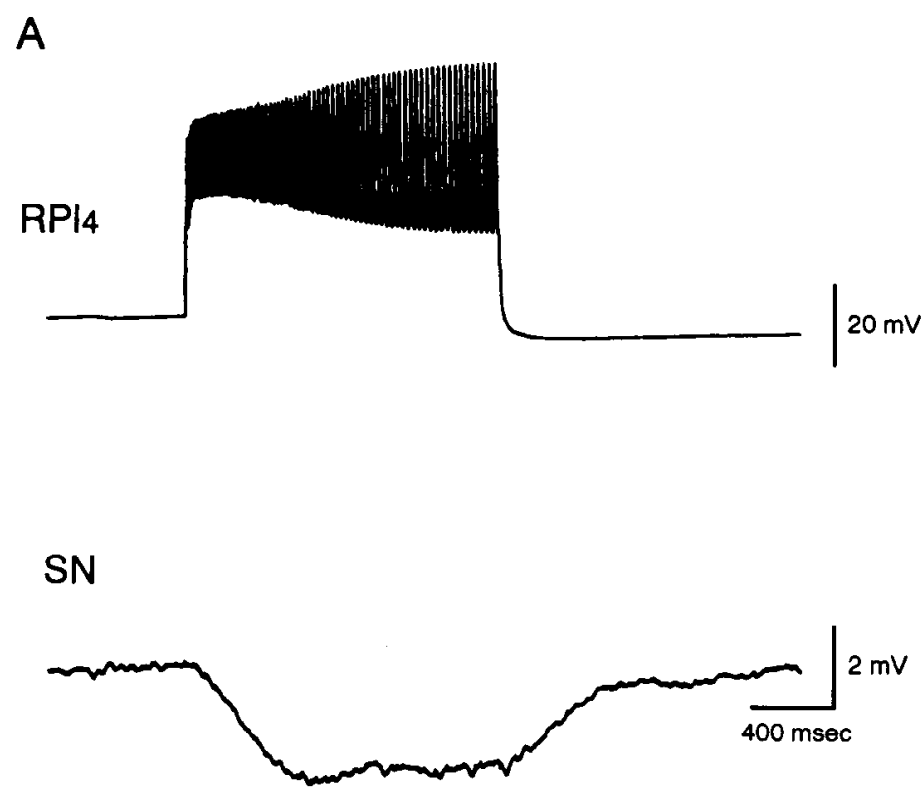

B
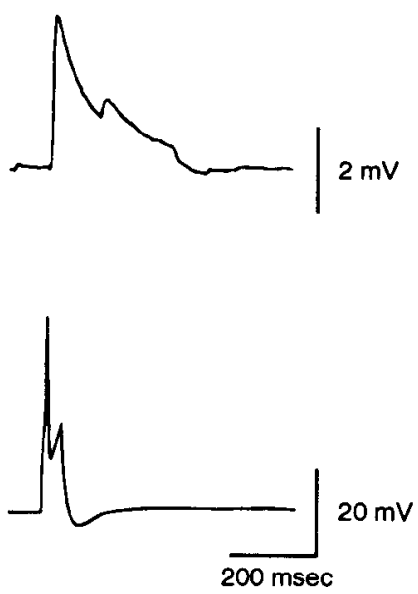

C

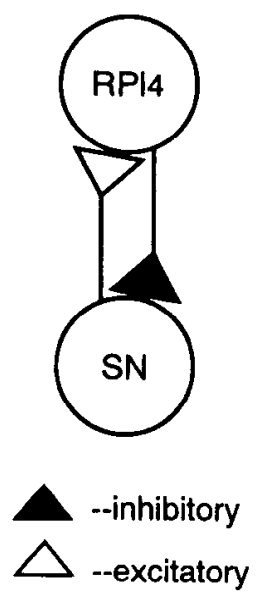

Figure 11. Some tail sensory neurons and $\mathrm{RPl}_{4}$ are reciprocally connected. $A$, A burst of spikes in $\mathrm{RPl}_{4}$ produced IPSPs in a sensory neuron. $B$, A single action potential in the same sensory neuron evoked a unitary EPSP in $\mathrm{RPl}_{4}$. Several small spontaneous EPSPs and IPSPs were also present. $C$, Schematic diagram of the synaptic interconnections of the $\mathrm{RPI}_{4}$ and the sensory neuron shown in $A$ and $B$.

perpolarization observed in a sensory neuron when a tactile stimulus is applied outside the sensory neuron's receptive field (see Discussion).

Synaptic connections between sensory neurons and $\mathrm{RPl}_{5}$ were not encountered. For each of five $\mathrm{RPl}_{5}$ neurons, connections with four to seven sensory neurons were tested. Additional experiments will be necessary to determine whether this apparent lack of connectivity is another difference between $\mathrm{RPl}_{4}$ and $\mathrm{RPl}_{5}$ or a sampling bias due to the lower number of experiments in which $\mathrm{RPI}_{5}$ was recorded.

\section{Discussion}

Although the elements of the monosynaptic circuit mediating the tail withdrawal reflex have been identified, other elements, that is, interneurons, appear to contribute to the circuit as well. For example, there is evidence that pleural excitatory interneuron $\mathrm{LPl}_{17}$ is activated by tail sensory neurons and produces EPSPs in tail motor neurons (Cleary and Byrne, 1993). The present study focused on neurons that were transiently excited by stimulation of peripheral nerves and that hyperpolarized tail sensory neurons as a result of intracellular stimulation. Several electrophysiological properties of $\mathrm{RPl}_{4}$, which was identified previously (Buonomano et al., 1992), were confirmed and examined in greater detail. In addition, $\mathrm{RPI}_{5}$ was identified and characterized for the first time. The properties of $\mathrm{RPl}_{4}$ and $\mathrm{RPl} \mathrm{I}_{5}$ are summarized in Table 1.

$\mathrm{RPl}_{4}$ and $\mathrm{RPl}_{5}$ had several features in common, including location in the rostral cluster on the ventral surface of the right pleural ganglion and hyperpolarizing output to pleural sensory neurons. They could be distinguished based on cross-reactivity with an antibody to FMRFamide. Confirming preliminary results (Buonomano et al., 1992), $\mathrm{RPl}_{4}$ did not react with the antibody. Other neurons with similar properties did react with this antibody, however, and these were identified as $\mathrm{RPl}_{5}$.

\section{Further characterization of $\mathrm{RPl}_{4}$}

As described previously (Buonomano et al., 1992), $\mathrm{RPl}_{4}$ also hyperpolarized tail motor neurons located in the pedal ganglion. This property of $\mathrm{RPl}_{4}$ was confirmed by the present study. Moreover, morphological experiments in this study showed that most of the dye-filled neurons projected into the pedal ganglion (14 of 16). The lack of a dye-filled projection in the remaining two neurons was probably due to technical factors such as erratic filling with Lucifer yellow or damage to the tissue during processing. An alternative possibility is that only a subset of $\mathrm{RPl}_{4}$ neurons project to the pedal ganglion. Neurons that did not have axons in the pleural-pedal connective would presumably inhibit motor neurons through a polysynaptic pathway, how-

Table 1. Comparison between $\mathrm{RPI}_{4}$ and $\mathrm{RPI}_{5}$

\begin{tabular}{lll} 
Properties & $\mathrm{RPl}_{4}$ & $\mathrm{RPI}_{5}$ \\
\hline Transmitter candidate & Not FMRFa & FMRFa \\
Connections to SNs & Fast IPSP & Slow IPSP \\
Connections to MNs & Fast IPSP & None \\
$\begin{array}{c}\text { Connections from SN } \\
\text { Axons in nerves and }\end{array}$ & Yes & No? \\
$\quad$ connectives & & \\
P8 & Yes & No \\
P9 & Yes & No \\
Pleural-abdominal & Yes & Yes \\
Pleural-pedal & Yes & No \\
Pleural-cerebral & Yes & Yes \\
Synaptic input & & \\
P8, P9 & Fast E-fast l & Fast E-slow 1 \\
Pleural-abdominal & & \\
connective & Fast E-fast l & Fast E-slow 1 \\
\hline
\end{tabular}


A1

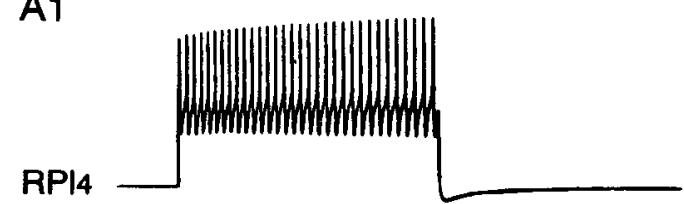

1

$20 \mathrm{mV}-2 \mathrm{mV}$

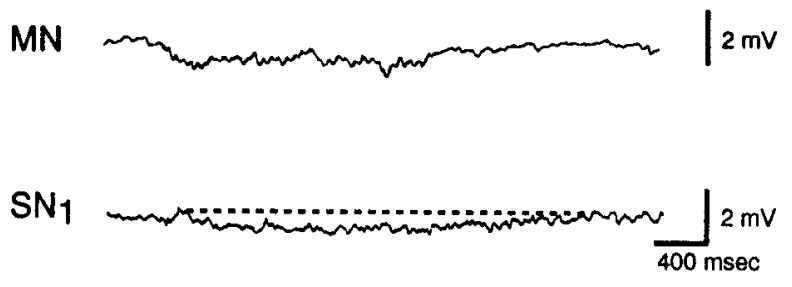

B1
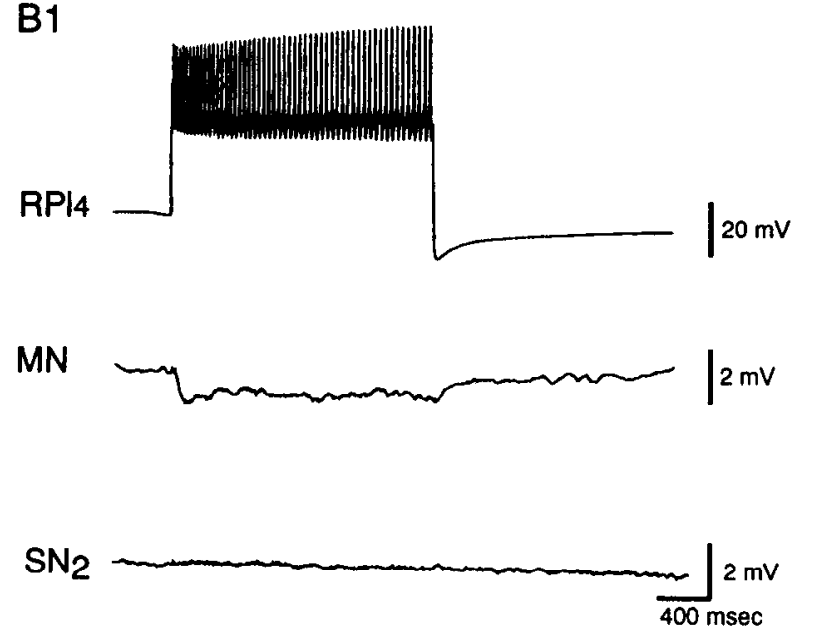

B2

A2
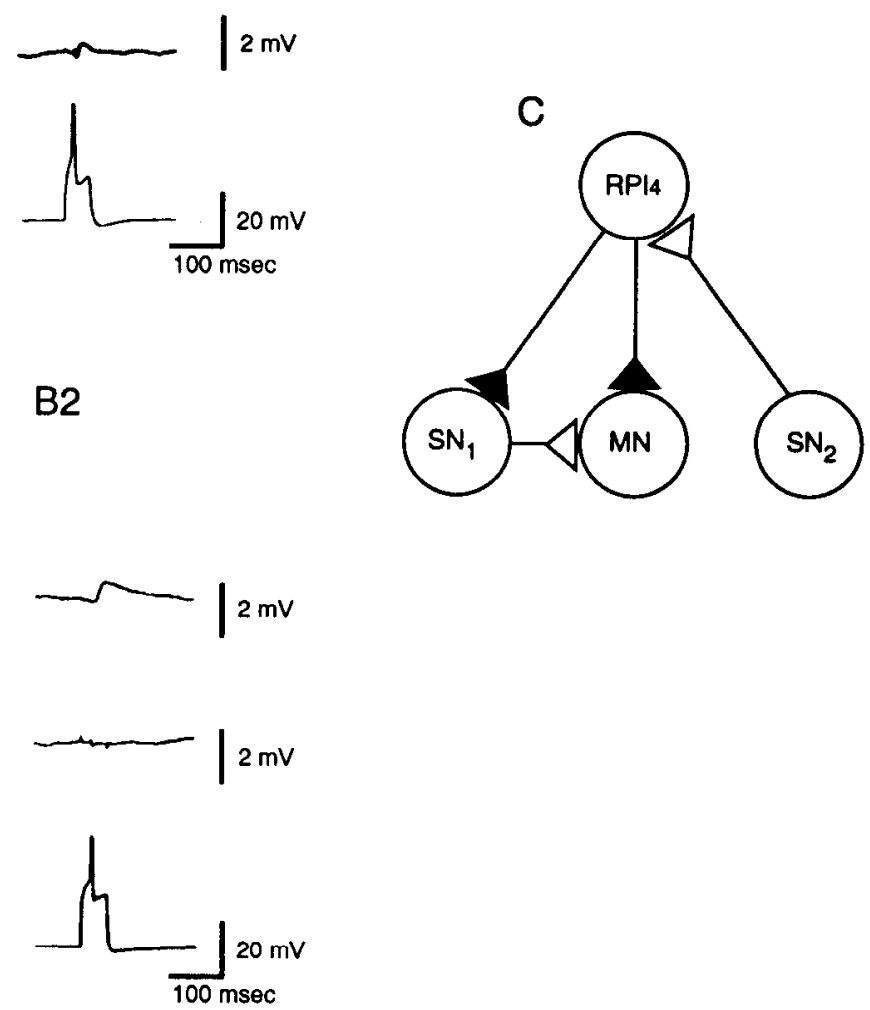

Figure 12. Sensory neurons and $\mathrm{RPl}_{4}$ are interconnected. $A 1, \mathrm{~A}$ burst of spikes in $\mathrm{RPl}_{4}$ produced IPSPs in sensory neuron $1\left(S N_{l}\right)$ and a motor neuron. $A 2$, A single action potential triggered in $\mathrm{SN}_{1}$ failed to evoke an EPSP in the inhibitory interneuron, but produced an EPSP in the motor neuron. $B 1, \mathrm{~A}$ burst of spikes in the same $\mathrm{RPl}_{4}$ shown in $A$ did not produce noticeable hyperpolarization in sensory neuron $2\left(S N_{2}\right)$, but still produced IPSPs in the motor neuron. $B 2, \mathrm{~A}$ single action potential triggered in $\mathrm{SN}_{2}$ evoked an EPSP in $\mathrm{RPl}_{4}$, but not in the motor neuron. $C$, Schematic diagram of the synaptic interconnections of the $\mathrm{RPl}_{4}$ with the motor neuron and two sensory neurons shown in $A$ and $B$.

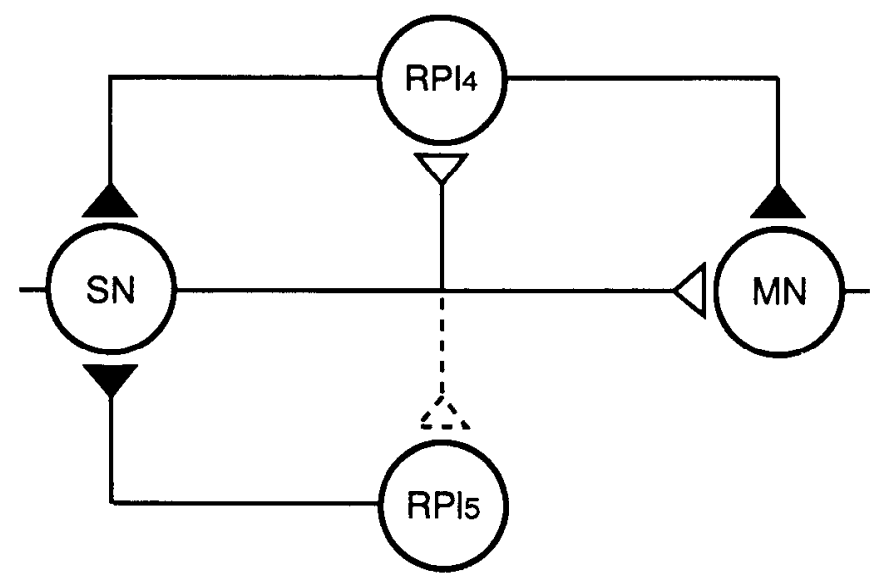

Figure 13. Schematic representation of interaction among a sensory neuron, $\mathrm{RPl}_{5}, \mathrm{RPl}_{4}$, and motor neuron in the neural circuit underlying the tail withdrawal reflex. See Discussion for details. ever, since tail motor neurons do not project into the pleural ganglion (Cleary and Byrne, 1984). In this study, electrophysiological experiments revealed that a subset of $\mathrm{RPl}_{4}$ appeared to project through the pedal ganglion and, in some cases, out peripheral nerves P8 and P9 (11 of 29). Further experiments will be necessary to demonstrate whether these axons actually reach the body wall where they could function as sensory or motor neurons. $\mathrm{RPl}_{4}$ also projected to the cerebral and abdominal ganglia, but synaptic connections with neurons in these ganglia were not examined in this study.

$\mathrm{RPl}_{4}$ receives excitatory inputs as a result of mechanical stimulation of the skin of the tail (Buonomano et al., 1992). This is consistent with the transient excitation that was elicited by electrical stimulation of pedal nerves P8 and P9 in this study. Electrical stimulation of P8 and P9 also elicited a late, short hyperpolarization component which was not observed after skin stimulation (Buonomano and Byrne, personal communication). Therefore, the inhibition appears to be due to recruitment of inhibitory neurons by the relatively nonspecific nerve stimulation. Excitatory inputs to $\mathrm{RPl}_{4}$ appear to be due, at least in 
part, to the activity of pleural sensory neurons (see below). Stimulation of the pleural-abdominal connective elicited a similar excitation-inhibition response in $\mathrm{RPl}_{4}$.

The neurotransmitter contained in $\mathrm{RPl}_{4}$ is not known. Candidates include dopamine (Abrams et al., 1984; Montarolo et al., 1988), histamine (Kretz et al., 1986; Chiel et al., 1988), myomodulin (Rosen et al., 1989; Critz et al., 1991), and GABA (King and Carpenter, 1989). $\mathrm{RPl}_{4}$ is unlikely to contain $\mathrm{GABA}$ or dopamine, since there are no cell bodies containing these transmitters in the pleural ganglion (Tritt et al., 1983; Cleary and Li, 1990). Myomodulin- and histamine-immunoreactive cell bodies have been found in the pleural ganglion (Elste et al., 1990; Miller et al., 1991), but $\mathrm{RPl}_{4}$ did not react with antibodies directed against these transmitters. Other candidates include $\mathrm{ACh}$, arginine vasotocin, and $\beta$-bag cell peptide since these transmitters can either hyperpolarize sensory neurons (Ichinose et al., 1988) or reduce the effectiveness of synaptic transmission between sensory and motor neurons (Goldberg et al., 1987; Goldsmith and Byrne, 1993). ACh is an interesting candidate because it is released by L16 in the abdominal ganglion (Segal and Koester, 1982). L16 appears to share some functional similarities with $\mathrm{RPl}_{4}$ and is an element of the circuit mediating siphon-gill withdrawal and ink release (Byrne, 1980a, 1981; Hawkins et al., 1981a). ACh is also the neurotransmitter contained in L24 (Segal and Koester, 1982), which inhibits gill motor neuron $\mathrm{LD}_{G 1}$ and $\mathrm{LD}_{\mathrm{G}}$ ? and produces conjoint excitation and inhibition in gill motor neuron L7 (Byrne and Koester, 1978; Byrne, 1983).

\section{Identification of $\mathrm{RPl}_{5}$}

$\mathrm{RPl}_{5}$ was distinguished from $\mathrm{RPl}_{4}$ by its ability to bind an antibody directed against FMRFamide. In addition, there were several distinctive electrophysiological properties of $\mathrm{RPl}_{5}$. Whereas both $\mathrm{RPl}_{4}$ and $\mathrm{RPI}_{5}$ produced IPSPs in pleural sensory neurons, the time courses of these summated IPSPs were different. Specifically, the times for both hyperpolarization and repolarization of the IPSPs in sensory neurons produced by $\mathrm{RPl}_{5}$ were slower. Unlike $\mathrm{RPl}_{4}, \mathrm{RPl}_{5}$ did not hyperpolarize tail motor neurons. This result was consistent with the failure of intracellular labeling to reveal an axon from $\mathrm{RPl}_{5}$ in the pleural-pedal connective. $R P l_{5}$ received transient excitatory synaptic inputs as a result of stimulating pedal nerves $\mathrm{P} 8$ and $\mathrm{P} 9$ and the pleuralabdominal connective, but excitatory inputs from pleural sensory neurons were not observed. Thus, the source of excitatory inputs remains unknown. The transient excitatory inputs were followed by a late hyperpolarization of much longer duration than that occurring in $\mathrm{RPl}_{4}$. This late hypcrpolarization appeared to be synaptically driven. The neurons mediating this late hyperpolarization are unknown. Like $\mathrm{RP}_{4}, \mathrm{RP} 1_{5}$ projected to the cerebral and abdominal ganglia.

The ability of $\mathrm{RPl}_{5}$ to bind to an antibody directed against FMRFamide suggests that this transmitter is released as a result of intracellular stimulation. This idea is supported by the fact that inhibitory effects of $\mathrm{RP}_{5}$ on sensory neurons have a relatively slow time course, as exogenous application of FMRFamide does (Belardetti et al., 1987; Ichinose and Byrne, 1991). In general, the responses of neurons to peptides are usually slow and long-lasting (Kupfermann, 1979; Hökfelt, 1991). Additional experiments will be necessary to prove that these physiological effects occur by modulation of the same channel, for example. Although $\mathrm{RPl}_{5}$ neurons were FMRFamide immunoreactive, additional biochemical experiments will be necessary to prove that the authentic peptide is synthesized by these neurons. There is a large family of peptides with structures similar to that of FMRFamide that may cross-react with the antibody, but have different pharmacological effects (Greenberg et al., 1983; Brezina et al., 1987; Norris et al., 1990).

The FMRFamide immunoreactivity of $\mathrm{RPl}_{5}$ suggests that it may be the contralateral homologue of $\mathrm{LPl}_{16}$, which is located in the left pleural ganglion and which inhibits the connections between sensory and motor neurons in the abdominal ganglion (Mackey et al., 1987; Small et al., 1992). Both neurons project to the pleural-abdominal connective, and both receive excitatory synaptic input from stimulation of peripheral nerve P9. One difference between the two neurons, however, is the projection of $\mathrm{LPl}_{16}$, but not $\mathrm{RPl}_{5}$, through the pleural-pedal connective. Functionally, it is not known whether $\mathrm{RPl}_{5}$ shares the ability of $\mathrm{LPl}_{16}$ to produce presynaptic inhibition. Comparison is difficult because the effects of $\mathrm{I} . \mathrm{Pl}_{16}$ on the tail sensory-motor synapse are not known; neither are the effects of $\mathrm{RPl}_{5}$ on either the tail or mantle circuits. Nevertheless, $\mathbf{R P l}_{5}$ may modulate the tail sensory-motor connection in numerous ways (see below). Additional experiments will be required to explore this homology in greater detail.

\section{Contribution of inhibitory interneurons to the neural circuitry underlying the tail withdrawal reflex}

This study extends previous results suggesting that the monosynaptic circuit underlying the tail withdrawal reflex is modulated by interneurons (Buonomano et al., 1992; Cleary and Byrne, 1993). A simplified circuit diagram is illustrated in Figure 13. Tail sensory neurons make excitatory synaptic connections with both tail motor neurons and $\mathrm{RPl}_{4}$. A connection from sensory neurons to $\mathrm{RPl}_{5}$ has not been demonstrated (dashed line), but this may have been due to the smaller number of pairwise recordings. $\mathrm{RP}_{5}$ only produced inhibition of the sensory neuron, whereas $\mathrm{RPl}_{4}$ produced both feedback inhibition of the sensory neuron and feedforward inhibition of the motor neuron. $\mathrm{RPl}_{4}$ may also be activated by sensory neurons that are not its followers. Thus, the inhibitory interneuron may play a role in hyperpolarizing a sensory neuron when a cutaneous stimulus is applied outside the sensory neuron's receptive field (Walters et al., 1983).

The electrophysiological properties of $\mathrm{RP}_{4}$ in the pleural ganglion appear similar to L16 in the abdominal ganglion, which is an element of the circuit mediating the siphon-gill withdrawal reflex (Byrne, 1981; Hawkins et al., 1981a; Wright and Carew, 1990) and inking (Byrne, 1980a). L16 is activated monosynaptically by LE sensory neurons in the abdominal ganglion and produces feedback inhibition onto LE sensory neurons. L16 also produces feedforward inhibition in both gill motor neuron L7 and ink motor neuron L14 (Byrne, 1981) as well as excitatory interneurons L29 and L34 (W. N. Frost, personal communication).

At present, the functional significance of hyperpolarization in the somata of sensory neurons is not known. However, there are three mechanisms by which hyperpolarization can affect the function of sensory neurons. First, hyperpolarization of the presynaptic membrane potential reduces transmitter release from sensory neurons (Hammer et al., 1989; Edmonds et al., 1990). This is a mechanism by which $\mathrm{L} 32$ reduces the release of transmitter from L10 (Byrne, 1980b). This form of depression appears to be due to voltage-dependent modulation of steady-state $\mathrm{Ca}^{2+}$ and $\mathrm{K}^{+}$currents (Shimahara and Peretz, 1978; Shapiro et 
al., 1980). Second, hyperpolarization of sensory neurons could contribute to conduction block that was observed following strong tactile stimuli (Clatworthy and Walters, 1993). Third, the hyperpolarization produced by FMRFamide application appeared to be due to opening of $\mathrm{K}^{+}$channels that also decreased excitability of sensory neurons (Belardetti, et al., 1987; Critz, et al., 1991). The effects of FMRFamide in the nervous system of Aplysia were mediated by arachidonic acid metabolites acting as second messengers (Piomelli et al., 1987). In addition to producing feedback inhibition of the sensory neurons, $\mathrm{RPl}_{4}$ also produced feedforward inhibition of the motor neurons. Previous evidence showed that the hyperpolarization in motor neurons produced by $\mathrm{RPl}_{4}$ was associated with an increase in membrane conductance of the motor neurons (Buonomano et al., 1992). Shunting of the postsynaptic current may decrease the amplitude of the EPSP and reduce the probability that motor neurons generate action potentials.

$\mathrm{RPl}_{4}$ could have peripheral effects as well. One possibility is that axons from $\mathrm{RPl}_{4}$ project to the body wall through peripheral nerves and conduct information from the periphery back to the pleural ganglion. Only primary sensory neurons have been shown to function in this way, however. Alternatively, the $\mathrm{RPl}_{4}$ may have a motor function. For example, L10, a major multifunction interneuron in the abdominal ganglion, sends axonal branches out the pericardial nerve and directly excites the opener muscle of the renal pore (Koester and Alevizos, 1989). Projections to the body wall may also have modulatory effects on terminals of sensory or motor neurons or on the muscle itself (Weiss et al., 1978; Billy and Walters, 1989). This would be similar to the serotonergic $\mathrm{C} 1$ neuron in the cerebral ganglion that synapses with follower neurons in the buccal ganglion and innervates buccal muscle as well (Weiss et al., 1978).

Inhibitory interneurons, through their feedback connections to sensory neurons and feedforward connections to motor neurons, are well poised to exert a powerful effect on mediating and modulating the responses to tail stimulation. Given this central role in the circuit, it is intriguing to speculate that the inhibitory interneurons may be a site of plasticity for circuits modulating the tail withdrawal reflex. Preliminary results suggest that application of 5-HT, which facilitates the connection between sensory and motor neurons, hyperpolarized $\mathrm{RPl}_{4}$, inhibited its spontaneous activity and decreased its excitability. In addition, 5-HT decreased the hyperpolarization produced by $\mathrm{RP}_{4}$ in sensory and motor neurons (Xu et al., 1992). This effect of 5-HT on $\mathrm{RPl}_{4}$ was similar to the effects of 5-HT on the abdominal inhibitory interneuron L30 (Frost et al., 1988). In the abdominal ganglion, application of 5-HT decreased the amplitude of IPSPS produced by L30 in L29, and the spike afterhyperpolarization of L30 was also reduccd. Thus, 5-HT may have multiple synergistic actions that contribute to modulation of the tail withdrawal circuit. In addition to facilitation of the sensory-motor neuron synapse, 5-HT may reduce the effectiveness of inhibitory neurons themselves and their associated connections with tail sensory and motor neurons. Studies examining the modulation of inhibitory interneurons may provide insight into the plasticity of the inhibitory processes that may contribute to sensitization.

\section{References}

Abrams TW, Castellucci VF, Camardo JS, Kandel ER, Lloyd PE (1984) Two endogenous neuropeptides modulate the gill and siphon withdrawal reflex in Aplysia by presynaptic facilitation involving cAMPdependent closure of a serotonin-sensitive potassium channel. Proc Natl Acad Sci USA 81:7956-7960.
Belardetti F, Siegelbaum SA (1988) Up- and down-modulation of single $\mathrm{K}^{+}$channel function by distinct second messengers. Trends Neurosci 11:232-238.

Belardetti F, Kandel ER, Siegelbaum SA (1987) Neuronal inhibition by the peptide FMRFamide involves opening of $\mathrm{S} \mathrm{K}^{+}$channels. $\mathrm{Na}-$ ture 325:153-156.

Billy AJ, Walters ET (1989) Modulation of mechanosensory threshold in Aplysia by serotonin, small cardioactive peptide ${ }_{\mathrm{B}}\left(\mathrm{SCP}_{\mathrm{B}}\right)$, FMRFamide, acetylcholine, and dopamine. Neurosci Lett 105:200204.

Brezina V, Eckert R, Erxleben C (1987) Modulation of potassium conductances by an endogenous neuropeptide in neurones of Aplysia californica. J Physiol (Lond) 382:267-290.

Brown RO, Gusman D, Basbaum AI, Mayeri E (1985) Identification of Aplysia neurons containing immunoreactive FMRFamide. Neuropeptides 6:517-526.

Buonomano DV, Cleary LJ, Byrne JH (1992) Inhibitory neuron produces heterosynaptic inhibition of the sensory-to-motor neuron synapse in Aplysia. Brain Res 577:147-150.

Byrne JH (1980a) Neural circuit for inking behavior in Aplysia californica. J Neurophysiol 43:896-911.

Byrne JH (1980b) Identification of neurons contributing to presynaptic inhibition in Aplysia californica. Brain Res 199:235-239.

Byrne JH (1981) Comparative aspects of neural circuits for inking behavior and gill withdrawal in Aplysia californica. J Neurophysiol 45:98-106.

Byrne JH (1983) Identification and initial characterization of a cluster of command and pattern-generating neurons underlying respiratory pumping in Aplysia californica. J Neurophysiol 49:491-508.

Byrne JH, Koester J (1978) Respiratory pumping: neuronal control of a centrally commanded behavior in Aplysia. Brain Res 143:87105.

Byrne JH, Castellucci VF, Kandel ER (1978) Contribution of individual mechanoreceptor sensory neurons to defensive gill-withdrawal in Aplysia. J Neurophysiol 41:418-431.

Chiel HJ, Kupfermann I, Weiss KR (1988) An identified histaminergic neuron can modulate the outputs of buccal-cerebral interneurons in Aplysia via presynaptic inhibition. J Neurosci 8:49-63.

Clatworthy AL, Walters ET (1993) Activity-dependent depression of mechanosensory discharge in Aplysia. J Neurophysiol 70:1 195-1209.

Cleary LJ, Byrne JH (1984) Light and electron microscopic examination of sensory neurons and motoneurons mediating the tail withdrawal reflex in Aplysia. Soc Neurosci Abstr 10:916.

Cleary LJ, Byrne JH (1993) Identification and characterization of a multifunction neuron contributing to defensive arousal in Aplysia. $\mathrm{J}$ Neurophysiol 70:1767-1776.

Cleary LJ, Li T (1990) Distribution of GABA in the pleural-pedal ganglia of Aplysia. Soc Neurosci Abstr 16:549.

Critz SD, Baxter DA, Byrne JH (1991) Modulatory effects of serotonin, FMRFamide, and myomodulin on the duration of action potentials, excitability, and membrane currents in tail sensory neurons of Aplysia. J Neurophysiol 66:1912-1926.

Elste A, Koester J, Shapiro E, Panula P, Schwartz JH (1990) Identification of histaminergic neurons in Aplysia. J Neurophysiol 64:736744.

Frost WN, Clark GA, Kandel ER (1988) Parallel processing of shortterm memory for sensitization in Aplysia. J Neurobiol 19:297-334.

Goldberg J, Colmers W, Edstrom J, Lukowiak K (1987) Suppression of sensory to motor synaptic transmission and narrowing of the sensory neurone action potential by arginine vasotocin in Aplysia californica. J Exp Biol 128:47-62.

Goldsmith JR, Byrne JH (1993) Bag cell extract inhibits tail-siphon withdrawal reflex, suppresses long-term but not short-term sensitization and attenuates sensory-to-motor neuron synapses in Aplysia. I Neurosci 13:1688-1700.

Greenberg MJ, Painter SD, Doble KE, Nagle GT, Price DA, Lehman HK (1983) The molluscan neurosecretory peptide FMRFamide: comparative pharmacology and relationship to the enkephalins. Fed Proc 42:82-86.

Hammer M, Cleary LJ, Byrne JH (1989) Serotonin acts in the synaptic region of sensory neurons in Aplysia to enhance transmilter release. Neurosci Lett 104:235-240.

Hawkins RD, Castellucci VF, Kandel ER (1981a) Interneurons involved in mediation and modulation of gill-withdrawal reflex in Aplysia. I. Identification and characterization. J Neurophysiol 45:304314. 
Hawkins RD, Castellucci VF, Kandel ER (1981b) Interneurons involved in mediation and modulation of gill-withdrawal reflex in Aplysia. II. Identified neurons produce heterosynaptic facilitation contributing to behavioral sensitization. J Neurophysiol 45:315-326.

Hökfelt T (1991) Neuropeptides in perspective: the last ten years. Neuron 7:867-879.

Ichinose M, Byrne JH (1991) Role of protein phosphatases in the modulation of neuronal membrane currents. Brain Res 549:146-150.

Ichinose M, Sawada M, Maeno T (1988) An acetylcholine-induced potassium current in tail sensory neurons in the pleural ganglion of Aplysia. Jpn J Physiol 38:563-568.

King WM, Carpenter DO (1989) Voltage-clamp characterization of $\mathrm{Cl}^{-}$conductance gated by GABA and L-glutamate in single neurons of Aplysia. J Neurophysiol 61:892-899.

Kistler HB, Hawkins RD, Koester J, Steinbusch HWM, Kandel ER (1985) Distribution of serotonin-immunoreactive cell bodies and processes in the abdominal ganglion of mature Aplysia. J Neurosci $5: 72-80$.

Koester J, Alevizos A (1989) Innervation of the kidney of Aplysia by L10, the LUQ cells, and an identified peripheral motoneuron. J Neurosci 9:4078-4088.

Kretz. R, Shapiro F, Bailey CH, Chen M, Kandel FR (1986) Presynaptic inhibition produced by an identified presynaptic inhibitory neuron. II. Presynaptic conductance changes caused by histamine. J Neurophysiol 55:131-146.

Krontiris-Litowitz JK, Erikson MT, Walters ET (1987) Central suppression of defensive reflexes in Aplysia by noxious stimulation and by factors released from body wall. Soc Neurosci Abstr 13:815

Kupfermann I (1979) Modulatory actions of neurotransmitters. Annu Rev Neurosci 2:447-465.

Lo LT, Byrne JH, Cleary LJ (1987) Distribution of three modulatory transmitters within the pleural ganglion of Aplysia. Soc Neurosci Abstr 13:1073.

Mackey SL, Glanzman DL, Small SA, Dyke AM, Kandel ER, Hawkins RD (1987) Tail shock produces inhibition as well as sensitization of the siphon-withdrawal reflex of Aplysia: possible hehavioral role for presynaptic inhibition mediated by the peptide Phe-Met-Arg-Phe$\mathrm{NH}_{2}$. Proc Natl Acad Sci USA 84:8730-8734.

Marcus EA, Nolen TG, Rankin CH, Carew TJ (1988) Behavioral dissociation of dishabituation, sensitization, and inhibition in Aplysia. Science 241:210-213.

Miller MW, Alevizos A, Cropper EC, Vilim FS, Karagogeos D, Kupfermann I, Weiss KR (1991) Localization of myomodulin-like immunoreactivity in the central nervous system and peripheral tissues of Aplysia californica. J Comp Neurobiol 314:627-644.

Montarolo PG, Kandel ER, Schacher S (1988) Long-term heterosynaptic inhibition in Aplysia. Nature 333:171-174.

Norris BJ, Calabrese RL (1990) Action of FMRFamide on longitudinal muscle of the leech, Hirudo medicinalis. J Comp Physiol [A] 167: $211-224$

Ocorr KA, Byrne JH (1985) Membrane responses and changes in cAMP levels Aplysia sensory neurons produced by serotonin, tryptamine, FMRFamide and small cardioactive peptide $\mathrm{B}_{\mathrm{B}}\left(\mathrm{SCP}_{\mathrm{B}}\right)$. Neurosci Lett 55:113-118.

Pieroni JP, Byrne JH (1992) Differential effects of serotonin, FMRFamide, and small cardioactive peptide on multiple, distributed processes modulating sensorimotor synaptic transmission in Aplysia. J Neurosci 12:2633-2647.
Piomelli D, Volterra A, Dale N, Siegelbaum SA, Kandel ER, Schwartz JH, Belardetti F (1987) Lipoxygenase metabolites of arachidonic acid as second messengers for presynaptic inhibition of Aplysia sensory cells. Nature 328:38-43.

Rankin CH, Carew TJ (1988) Dishabituation and sensitization emerge as separate processes during development in Aplysia. J Neurosci 8:197211.

Rankin CH, Carew TJ (1989) Developmental analysis in Aplysia reveals inhibitory as well as facilitatory effects of tail shock. Behav Neurosci 103:334-344.

Rosen SC, Susswein AJ, Cropper EC, Weiss KR, Kupfermann I (1989) Selective modulation of spike duration by serotonin and the neuropeptides, FMRFamide, $\mathrm{SCP}_{\mathrm{B}}$, buccalin and myomodulin in different classes of mechanoafferent neurons in the cerebral ganglion of Aplysia. J Neurosci 9:390-402.

Segal MM, Koester J (1982) Convergent cholinergic neurons produce similar postsynaptic actions in Aplysia: implication for neural organization. J Neurophysiol 47:742-759.

Shapiro E, Castellucci VF, Kandel ER (1980) Presynaptic membrane potential affects transmitter release in an identified neuron in Aplysia by modulating $\mathrm{Ca}^{2+}$ and $\mathrm{K}^{+}$currents. Proc Natl Acad Sci USA 77: $629-633$.

Shimahara T, Peretz B (1978) Soma potential of an interneurone controls transmitter release in a monosynaptic pathway in Aplysia. Naturc 23:158-160.

Small SA, Cohen TE, Kandel ER, Hawkins RD (1992) Identified FMRFamide-immunoreactive neuron LPL16 in the left pleural ganglion of Aplysia produces presynaptic inhibition of siphon sensory neurons. J Neurosci 12:1616-1627.

Teyke T, Weiss KR, Kupfermann I (1990) An identified neuron (CPR) evokes neuronal responses reflecting food arousal in Aplysia. Science 247:85-87.

Tritt SH, Lowe IP, Byrne JH (1983) A modification of the glyoxylic acid induced histofluorescence technique for demonstration of catecholamines and serotonin in tissues of Aplysia californica. Brain Res 259:159-162.

Walters ET, Byrne JH, Carew TJ, Kandel ER (1983) Mechanoafferent neurons innervating tail of Aplysia: I. Response properties and synaptic conncctions. J Neurophysiol 50:1522-1542.

Weiss KR, Cohen JL, Kupfermann I (1978) Modulatory control of buccal musculature by a serotonergic neuron (metacerebral cell) in Aplysia. J Neurophysiol 41:181-203.

Weiss S, Goldberg JI, Chohan KS, Stell WK, Drummond GI, Lukowiak K (1984) Evidence for FMRFamide as a neurotransmitter in the gill of Aplysia californica. J Neurosci 4:1994-2000.

Wright WG, Carew TJ (1990) Contribution of interneurons to tailshock induced inhibition of the siphon withdrawal reflex in Aplysia. Soc Neurosci Abstr 16:20.

Wright WG, Marcus EA, Carew TJ (1991) A cellular analysis of inhibition in the siphon withdrawal reflex of Aplysia. J Neurosci 11: 2498-2509.

$\mathrm{Xu}$ Y, Cleary LJ, Byrne JH (1991) Identification of pleural neurons that inhibit tail sensory neurons of Aplysia: correlation with FMRFamide immunoreactivity. Soc Neurosci Abstr 17:1590.

Xu Y, Pieroni JP, Cleary LJ, Byrne JH (1992) Serotonin inhibits inhibitory interneurons in the neural circuitry for the tail-withdrawal reflex of Aplysia. Soc Neurosci Abstr 18:714. 